Check for updates

Cite this: Mater. Adv., 2021, 2,6885

Received 16th August 2021, Accepted 13th September 2021

DOI: 10.1039/d1ma00720c

rsc.li/materials-advances

\title{
Rational design and controllable synthesis of polymer aerogel-based single-atom catalysts with high loading
}

\author{
Zhi Chen, ${ }^{\text {ab }}$ Shu Zhang, ${ }^{b}$ Jian Yang, (D) ${ }^{b}$ Cheng Chen, (D) ${ }^{b}$ Yaochen Song, ${ }^{a b}$ \\ Caili Xu, ${ }^{b}$ Mengqiang Wu iD ${ }^{b}$ and Jiaxuan Liao (iD *ab
}

\begin{abstract}
Recently, single-atom catalysts (SACs) are of great interest in the field of catalysis. Current research shows that it is a potential and feasible development direction for precious metal materials to be made into SACs. Reducing the metal content as much as possible gives the single atom catalyst an obvious cost advantage. However, very low metal loading does not always provide sufficient catalytic activity for SACs. In some catalytic reactions, the deficiency of low catalyst loading can be offset by the increase in catalyst usage. But the excessive use of a catalyst may lead to the loss of mass transport and then the power density. The single atom and high loading might seem like a paradoxical concept but for catalysts, the sufficiently high specific catalytic activity evolves into a most critical parameter for SACs. Synthesizing high loading SACs under control will be an important direction in the next stage of development. In this review, we focus on the progress of precursor selection, material synthesis, content of single-atom, and some possible solutions for high loading SACs. Meanwhile, we also propose a single atom aerogel catalyst with high loading, which provides more possibility for the future development of catalysts.
\end{abstract}

\section{Introduction}

Single-atom catalysts (SACs) have attracted great attention in the field of catalysis. ${ }^{1-8}$ The performance of the catalyst depends on the number of active sites. The single atom catalyst can reduce the amount of the metal while ensuring multiple active sites in it, which makes it have a very competitive advantage. By selecting appropriate supports, SACs have been applied in diverse catalysis for material synthesis, photocatalytic reactions, electrocatalytic reactions, lithium-sulfur batteries, zinc air batteries, toxic gas adsorption, and fuel cells. ${ }^{9-20}$ In order to improve the performance of SACs, researchers have developed various new techniques such as the impregnated method, super mixer, electrofiltration method, high temperature shockwave, in situ photodeposition procedure, and high-temperature synthesis by arc-discharge strategy. ${ }^{21-27}$ Furthermore, additives have been incorporated into the composites to enhance the performance of SACs. The most commonly used synergists or carriers, which serve as hosts and provide stable sites for atoms, include

\footnotetext{
${ }^{a}$ Yangtze Delta Region Institute (Quzhou), University of Electronic Science and Technology of China, Quzhou, Zhejiang 324000, China.

E-mail: jxliao@uestc.edu.cn

${ }^{b}$ School of Materials and Energy, University of Electronic Science and Technology of China, Chengdu 611731, People's Republic of China
}

graphene, carbon nanotubes, porous carbon, aerogels, oxides, nitride, sulfides, and alloys. ${ }^{10,28-38}$ Among these materials, aerogels show unique properties that are suitable for the catalyst carrier, such as large specific surface area, tailorable porosity, efficient separation of metal atoms, and chemical/physical stability. ${ }^{39-45}$

It is worth mentioning that through different processes and composite modification, the properties of SACs have been significantly improved. However, challenges still remain from laboratory to real engineering. To realize the engineering of SACs, the following requirements such as environmentfriendliness, low cost, and good catalytic performance should be fulfilled. At present, SACs are still the state-of-the-art catalysts, which cannot meet all the above requirements. The main challenges are the high cost of the raw materials, and the very complex preparation process, or the low yield; these are the obstacles that cannot get around the engineering road of single atom catalysts. The catalytic performance of SACs, are affected by multiple factors including the elemental content, specific surface area, micro-morphology, and particle size. In this context, the loading of single atoms on SACs is a crucial parameter but easy to be ignored. The importance of high loading of SACs (it is called densely packed SACs in some review) was previously reported in various recent reviews. ${ }^{46,47}$ Usually, when researchers consider the sustainable development 
of catalysts, the metal atoms in the catalyst are kept as low as possible. However, very low metal content does not always provide sufficient catalytic activity for SACs.

In many catalytic reactions, the deficiency of low metal loading can be offset by the increase in the catalyst usage. However, this method of simply increasing the amount of the catalyst can only improve the catalytic activity to a certain extent, and with the increase in the amount of the catalyst, the specific activity of the catalyst also decreased gradually, such as in proton exchange membrane fuel cell (PEMFC), although the excessive usage of catalysts can make up for the performance loss of low metal-loading, and the thick catalyst layer would lead to the loss of mass transport and then the power density. The unique advantage of SACs with high loading is that they maintain the high specific activity of the catalyst. The catalyst with high specific activity can significantly reduce the amount of the catalyst and reduce the quality of the whole device, thus improving the energy density and power density of the device. In addition, the high loading of SAC is also important for establishing cooperative effects between the SACs. By developing materials with ligands, metal atoms in different valence states can coordinate and prevent leaching or nanoparticle formation. Thus, the gap between homogeneous and heterogeneous catalysis can be closed. ${ }^{48}$ The controllable synthesis of high loading single atom catalysts will be an important direction in the next stage of development. At present, there is no clear definition for the SACs with high loading. This paper tentatively proposes that low loading is less than $1 \mathrm{wt} \%$, medium loading is 1-3 wt $\%$, and high loading is more than $3 \mathrm{wt} \%$.

Some reviews and perspectives about SACs and their applications have been published in recent years. To the best of our knowledge, there are no reviews that emphasize on the metal content and summarize the synthesis of high loading SACs in a controllable way. The SACs with high loading can greatly improve the catalytic activity of metal atoms and can simultaneously reduce the amount of the catalyst to reach the same catalytic effect. In this context, this review covers the scope of the research process on the preparation of SACs based on different technologies and carriers. We then primarily focus on adjusting and controlling the effective single atom loading of the SACs. In addition, based on the analysis and reasoning of the existing literature and further simulation calculation, a theoretically feasible preparation scheme for the aerogelsupported single atom catalyst is proposed. Through the implementation of this scheme, SACs can be synthesized in a controllable way in terms of the loading and specific surface area. Finally, the challenges and prospects for the future development of single atom catalysts are also presented.

\section{Synthesis of single atom catalysts}

The synthetic strategy plays an important role in the synthesis of SACs. The key with SAC materials is that it is difficult to guarantee atomic independence during the synthesis of SACs. Due to the relatively high surface energies of single metal atoms, various general synthetic strategies cannot be readily adopted for the synthesis of SACs. In recent years, some improvement methods based on traditional synthetic methods and some new synthetic methods have been gradually developed and applied in the synthesis of SACs, as shown in Fig. 1. The reported synthetic methods can be mainly divided into the following categories, including the homogeneous reaction method, the pyrolysis method, the high energy complex technique, and the mass selection with soft-landing method. The reported specific preparation processes are listed in Table 1, and the advantages and disadvantages of each synthetic method are also included.

(1) Homogeneous reaction method is a representative lowcost approach with the benefits of a simple preparation process and readily available precursors. The homogeneous reaction is also called the "single phase reaction", i.e., the chemical reaction only occurred in one phase (gas phase, liquid phase, or solid phase). It is characterized by the absence of a phase interface in the reactant system. For monoatomic catalysts, the homogeneous reaction mainly occurs in the liquid phase system. Catalyst ions or micro-nanoparticles and carriers are dispersed in the liquid phase system and bonded together by forming new chemical bonds or van der Waals forces. This type of method mainly includes coprecipitation synthesis, wet-impregnation synthesis, and solvothermal synthesis, and these synthetic reactions are usually carried out under mild conditions. ${ }^{49-51}$ During the homogeneous reaction, because most of the reactants are concentrated on the surface of the supports, once the ion concentration increases, the formed single atoms with high specific surface energy are extremely easy to agglomerate. ${ }^{52,53}$ Therefore, it is difficult to prepare high loading SACs for practical application using this method.

(2) High energy complex technique such as ball milling and anti-Ostwald method are likely to be used in large-scale synthetic SAC materials. High energy ball milling is also called mechanical alloying. High energy ball milling should be able to deliver high mechanical energy to the catalysts and supports powder in a short time so that the milled materials can realize mechanical alloying (mechanical activation) in a short time, even form nanocrystalline or amorphous materials, and reduce the oxidation and pollution of materials. However, this category has certain requirements for precursors and supports, which limits its application. ${ }^{54,55}$

(3) The pyrolysis method is usually a post-treatment method for the precursors. In the process of high temperature pyrolysis $\left(\geq 600{ }^{\circ} \mathrm{C}\right.$ ), isolated metal catalyst atoms can be directly doped into the carbon matrix or form strong coordination with carbon atoms, which provides the isolated metal atoms high stability. Based on the mechanisms of pyrolysis, new technologies have also been developed, such as high-temperature synthesis by arc-discharge strategy, high pressure heating reaction, and high temperature shockwave. ${ }^{21,25,57,58}$ These methods require a large number of mobile catalyst atoms and a support that can combine with the mobile catalyst atoms. At high temperature, volatile metal molecules are released and captured by the surface of the support; then, the single metal atom can be evenly dispersed on the surface of the support, thus forming 


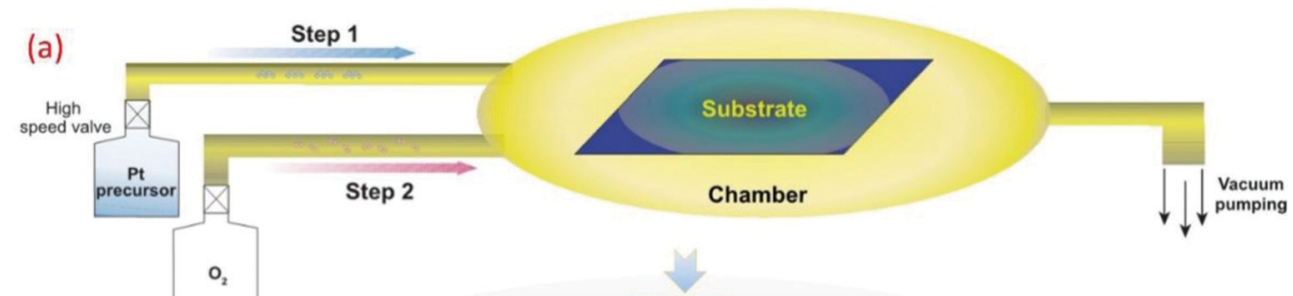

(b)

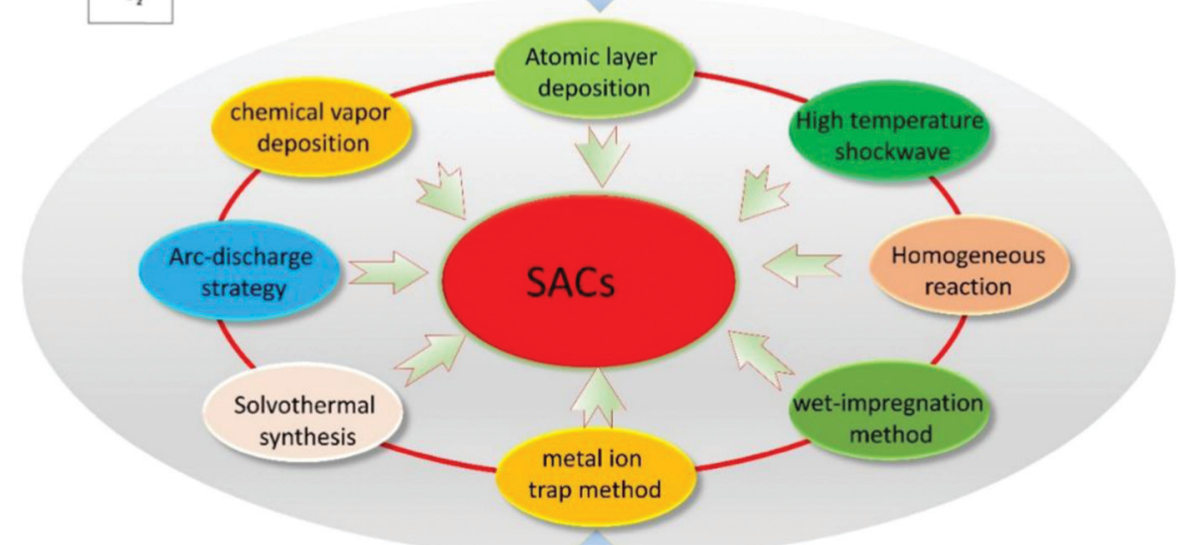

(c)

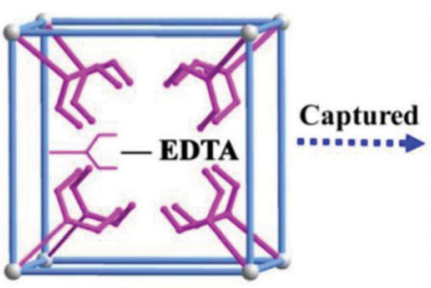

MOF-based trap

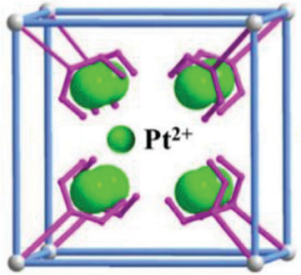

$P t^{2+}-S A s / M B T$

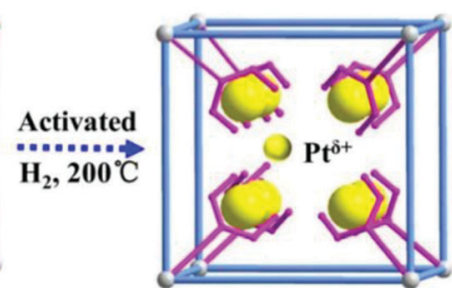

$P t-S A C s / M B T$

Fig. 1 (a) The schematic diagram of SACs prepared by the ALD method. ${ }^{56}$ Copyright 2018, Oxford University Press. (b) Some conventional and novel synthetic strategies for SACs. (c) The schematic illustration of single-atom Pt catalysts encapsulated in MOF-808-EDTA via the single metal ion trap method. ${ }^{23}$ Copyright 2019, Elsevier Inc.

Table 1 Metal loading and construction strategy in single atom catalysts

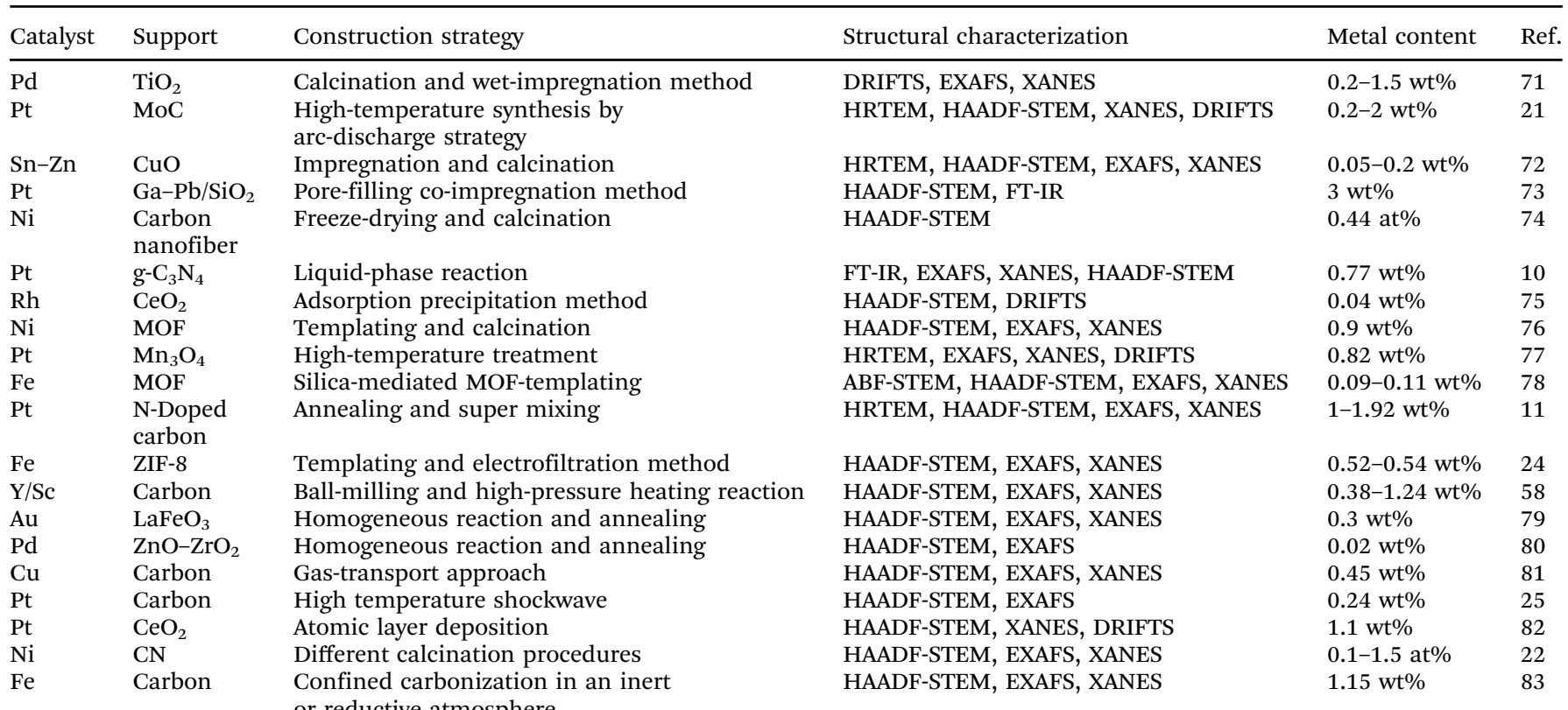


the SACs. The pyrolysis methods can afford SACs with high stability, high specific surface area, high metal loading, and unique micro hole-structure. ${ }^{59-62}$ However, this method is also not perfect. The formation of specific microstructures requires the use of template agents, high temperature treatment, and hazardous etching reagents (such as HF) to clean the material surface. Moreover, both the supports and metal atoms are produced simultaneously during the synthetic process, which makes it difficult to control the number of effective single atoms on the surface of the support and the number of single atoms with catalytic activity.

(4) Atomic layer deposition (ALD) is like an upgraded version of chemical vapor deposition (CVD); the difference is the deposition process between the pneumatolytic precursor and the support, evolving into multistep self-limiting surface reactions, which allows the metal atoms to be deposited more evenly on the surface of the support. ${ }^{63-66}$ ALD usually requires a two-step process, as shown in Fig. 1a; the first step is the reaction between the catalyst precursor and the support surface, and the second step is the conversion of the precursor by pulse energy. In the whole synthetic process, the design and control of the atomic level can be achieved by adjusting the cycle. ALD is a very promising technology but so far, it has been difficult to realize the mass production of SACs. On the one hand, the high requirement of this method for equipment conditions such as vacuum and elevated temperature leads to high cost; on the other hand, it is selective for material target and support, which makes this method usable only in part of material systems.

(5) Mass selection with soft-landing is a simple and straightforward technology, and it has been successfully applied for the synthesis of SACs. In this method, the pure metal solid is directly gasified in the inert gas and then deposited on the support with inert gas flow. The number of atoms can be controlled by the quality of the added metal solid. ${ }^{67,68}$ The number of atoms, regardless of single atom or multi-atom clusters, can be directly controlled by controlling the mass of the clusters in the flow. The high dependence on the complex equipment and low yield are the major deficiency of this method, which makes it difficult to achieve the mass production of SACs. In addition, because the catalyst atoms are adsorbed on the surface of the supports, no chemical bonds are formed, which will cause the catalyst atoms to fall off or agglomerate in the long-term catalytic process, resulting in a sudden decrease in the catalytic activity.

\section{Metal content in single atom catalysts}

With in-depth research, SAC materials have been synthesized in a variety of ways, as described above. When the content of the metal atoms is very low, the SACs can be easily synthesized by some specific methods. The commonly used characterization methods mainly include diffuse reflectance infrared Fourier transform spectroscopy (DRIFTS), extended X-ray absorption fine structure spectra (EXAFS), X-ray absorption near edge structure (XANES), high-resolution transmission electron microscopy (HRTEM), high-angle annular dark-field scanning transmission electron microscopy (HAADF-STEM), Fouriertransform infrared (FT-IR) spectroscopy, and annular brightfield scanning transmission electron microscopy (ABF-STEM). As shown in Table 1, sufficient evidence has been provided to prove the existence of single atoms by verification using a variety of characterization methods. The recent reports about SACs (Table 1) show that most SACs have an atomic loading of less than $3 \mathrm{wt} \%$. The present challenge is that it is difficult to maintain the independence of the metal single atoms with increasing metal atom content because high energy metal single atoms are easily migrated and agglomerated in synthesis or subsequent applications. Therefore, choosing suitable precursors is an important prerequisite for the successful synthesis of SAC materials. To this end, some strategies such as spatial constraint, coordination, and chemical bonding have been used to fix metal atoms at the support sites. ${ }^{69,70}$

The catalytic activity and cycling efficiency of the SAC materials and the power/energy density of the SAC-based equipment heavily depend not only on their intrinsic activity but also on the quantity of the catalytic sites. One key technical issue is balancing the relationship between the number of atoms and the agglomeration of atoms. In particular, metal atoms tend to migrate and agglomerate more easily during high-temperature processing, which further increases the difficulty of synthesizing high-loading SAC materials. The practical use of SACs is confined by limited active sites, which makes high-loading SACs attract more attention from researchers. Aiming at this problem, some potential solutions have been proposed. Wang et al. ${ }^{84}$ recently reported a two-step wet chemistry method for the synthesis of $\mathrm{Ir}-\mathrm{NiO} /$ carbon cloth, and the metal loading was increased to $18 \mathrm{wt} \%$ (Ir on the NiO). As shown in Fig. 2, the oxygen evolution reaction performance of the obtained SACs that exhibit significant improvement with the increase in the metal content. Zhao et al. ${ }^{85}$ reported a cascade anchoring strategy to synthesize SACs and realize high metal loading up to $12.1 \mathrm{wt} \%$, which indicated that the high-loading SACs possess better electrocatalytic performance for $\mathrm{O}_{2}$ reduction and $\mathrm{CO}_{2}$ reduction. These new attempts have provided scientists with new hope and great potential. Single-atom catalysts with high loading will become the focus of research in the future. Another challenge is the large-scale production; only when the SACs realize industrial production can it be applied in practice. Most synthetic processes of SACs require detailed multi-step regulation to obtain stable single atom sites, while mass production requires commercially available low-cost carriers and preparation processes, which can be scaled up. Therefore, it is highly desirable to develop a synthetic method suitable for the mass production of SACs with high metal loading in a controllable manner.

\section{Aerogel catalyst}

The effective catalytic area in a catalyst is as important as the high loading. For practical applications, the high metal content 
(a)

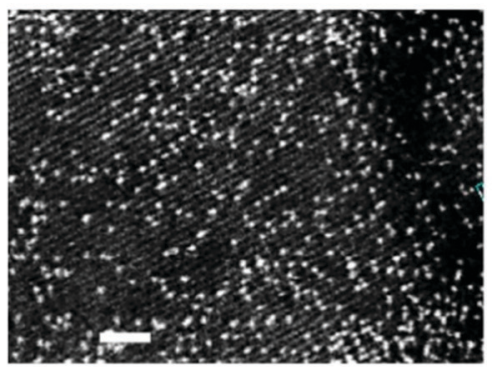

(d)

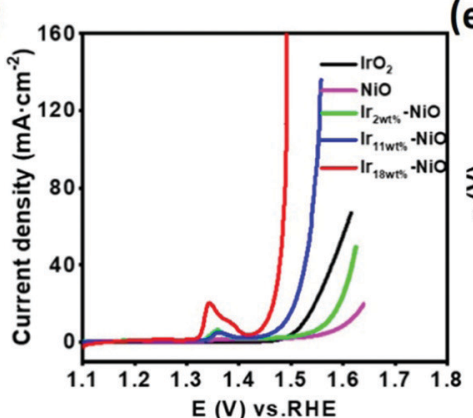

(g)

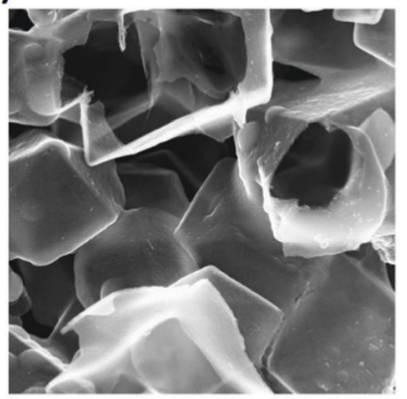

(b)

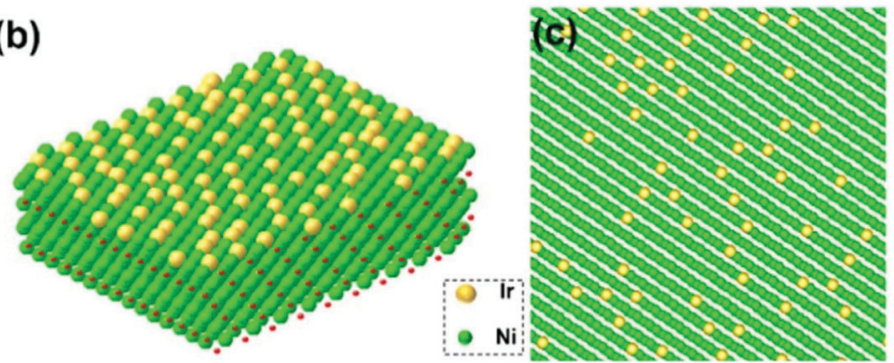

(e)

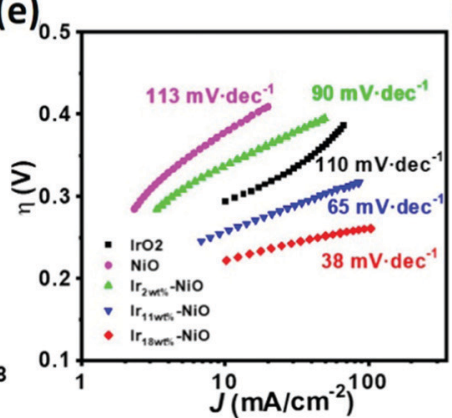

(h)

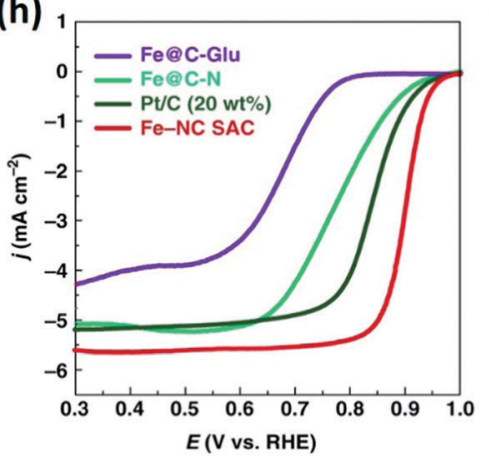

(f)

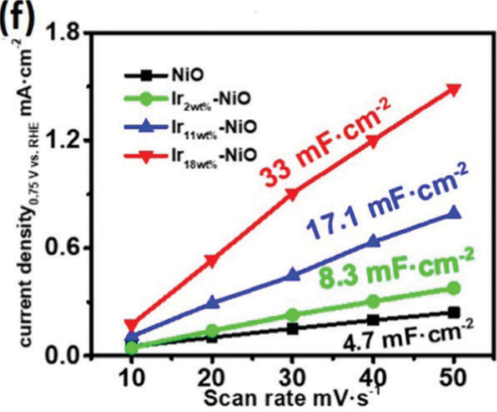

(i)

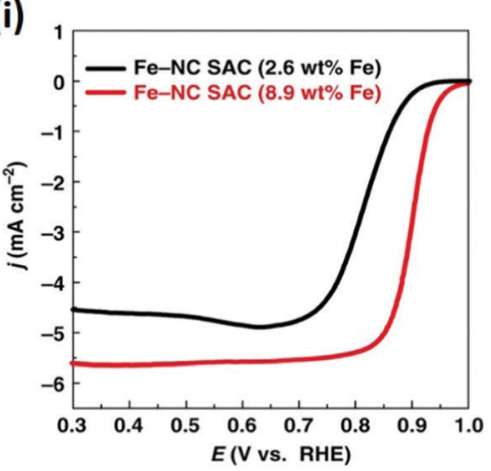

Fig. 2 High-loading SACs and their performance comparison with different metal contents. (a) HAADF-STEM micrographs of the catalyst. (b and c) Corresponding atomic models. (d) Polarization curves and (e) Tafel plots for OER. (f) The estimation of $C_{\text {dll }}{ }^{84}$ Copyright 2020, American Chemical Society. (g) SEM image of the support. (h) Steady-state ORR polarization curves of different SACs. (i) Steady-state ORR polarization curves of SACs with different Fe loadings. ${ }^{86}$ Copyright 2019, Nature.

in SAC materials is not sufficient for high efficiency catalysis. It is also of great importance to allow as many active sites as possible to be in full contact with the reaction product; thus, single atoms of the metal can provide enough catalytic activity. Among the many candidate support materials, aerogels nanoscale porous solid materials formed by the sol-gel process, in which the liquid phase in the gel is replaced by the gaseous phase (usually by air) through a certain drying method. ${ }^{87-89}$ Aerogels as the catalyst support materials demonstrate the indispensable advantages in comparison with other support materials. ${ }^{90-93}$ Before crystallization at high temperature, due to the three-dimensional porous structure of the aerogel materials, the metal atoms' composite in the aerogel are spatially isolated so that the agglomeration of the metal atoms can be restrained during the high-temperature process. Secondly, the obtained aerogel SACs possess higher surface area compared to normal particles; the greater contact of active sites leads to the sufficient use of the SACs catalytic properties. In addition, aerogels can also be produced as monolithic, flexible structures that can be used without the extra current collector, which will greatly reduce the overall mass of the catalyst devices and improve the bending resistance.

The aerogel catalyst support materials mainly include inorganic oxide-based aerogel and carbon-based aerogel. The typical properties of inorganic aerogels are high specific surface area and high porosity. In addition, some types of inorganic oxide-based aerogels can exhibit specific optical and thermodynamic properties. Compared with traditional inorganic aerogels (such as silica aerogels), carbon aerogels have many excellent properties and wider application prospects. Carbon aerogels have the advantages of good conductivity, large specific surface area, and wide range of density. They are ideal electrode materials for the preparation of the electrocatalyst support and electronic double layer capacitor. For different catalytic systems, the requirements of the catalyst support are also different. Electrocatalysis favors highly conductive substrates while photocatalysis requires substrates with an optical gap. In addition, there are also some characteristics such as 
mechanical properties, pore structure, hydrophobicity, biocompatibility, transparency, and thermal conductivity, which correspond to the needs of different fields. ${ }^{94}$ In the application, it is necessary to select the catalyst support according to the specific-use scenarios so as to achieve the best catalytic effect.

In a range of catalyst support materials, graphene has received considerable attention in the field of catalysis and has been widely studied. Recently, several articles have reported that graphene can improve the electrocatalytic properties of bird feces but according to the authors, researchers should also focus on other research directions, ${ }^{95}$ This may be a good suggestion, and it is going to make researchers rethink our attitudes to scientific research. We also believe that the essence of scientific research is to simplify problems, not to complicate them, and even bring the learned involution. The combination of single-atom catalysts and graphene aerogels is a very good innovation. In the short term, it is difficult to reduce the production cost of single-atom materials and graphene. With the development of technology and scale, these new materials and technologies will eventually highlight their value. As mentioned above, sufficient catalytic performance, low cost, and environmental friendliness are the three most necessary elements for the application of SACs. Although research has been widely carried out on single atom catalysts and graphene aerogel catalysts, there are much less reports on single atom catalysts supported by aerogels. This review will focus on the synergistic catalytic effects when combining aerogels with single atoms.

The preparation of the aerogel can be divided into three typical steps, namely, sol-gel, aging, and drying processes. ${ }^{96}$ For carbon-based aerogels, an additional carbonization step is required. Sol-gel process is the basic reaction to form a threedimensional skeleton precursor of the aerogel. In general, by controlling the temperature, $\mathrm{pH}$ value, or photoinitiation condition, individual molecules or ions can be complexed or crosslinked together to form a solid gel from a colloidal solution. As shown in Fig. 3, self-supporting 3D nanostructures can be formed from inorganic precursors, organic precursors, and inorganic/organic composite precursors, and the reaction can take place in aqueous solution systems and organic solutions. The transformation of the sol into the gel can be simply understood as hydrolysis, followed by a condensation reaction between organic and inorganic monomers. For example, the most typical silica aerogel sol gel formation process with tetramethyl orthosilicate (TMOS) as the precursor is shown in Fig. 3.

There are also some condensation reactions involving the process, in which the nucleophilic attack on the carbon centers can form three-dimensional networks in non-hydrolytic systems,

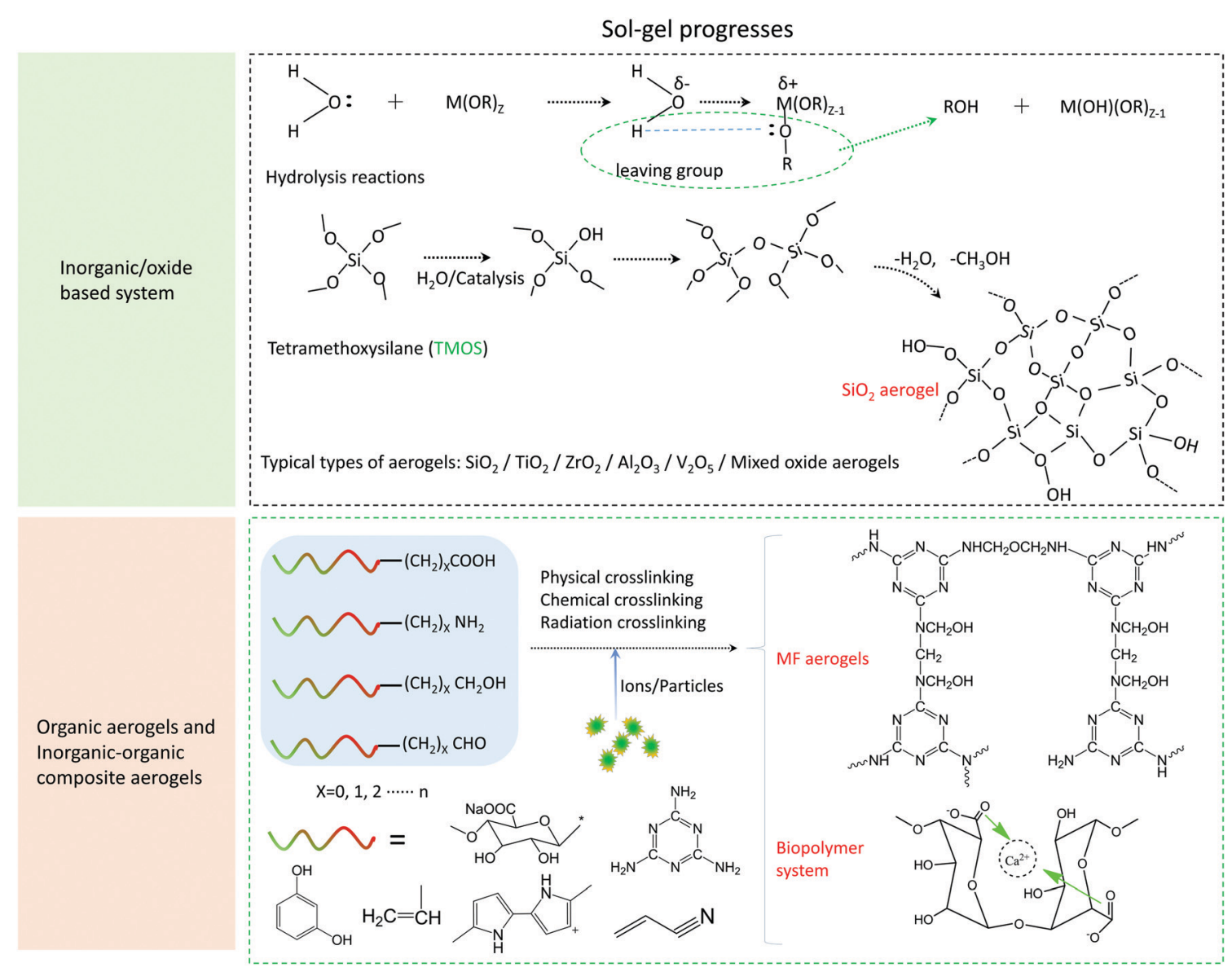

Fig. 3 The sol-gel process of aerogels. 
such as the formation of the oxygen bridge bonds by alcohols, ethers, or carboxylic acids, to synthesize anhydrous oxides. Detailed mechanism analysis as well as the respective advantages and disadvantages can be referred to in the paper of Mutin and Vioux. ${ }^{96}$ For organic molecular and biopolymer precursors (e.g., melamine formaldehyde (MF), resorcinol formaldehyde (RF), polysaccharides, and polypeptides), the condensation process that forms gel networks include physical polymerization represented by hydrogen bonds and chemical polymerization, which initiate crosslinking by light, heat, or $\mathrm{pH}^{97-100}$ The reaction process of two representative sol-gel processes of MF aerogels and biopolymer aerogels are shown in Fig. 3. The sol-gel process of the MF aerogel is through the formation of the diaminomethylmethyl bridge and the diaminomethylmethyl ether bridge under the catalysis of acid. Finally, the gel process is completed to form a 3D network structure. In addition to the crosslinking reactions and the dehydration condensations, alginate polymers can also combine with multivalent cations to realize the sol-gel process. ${ }^{101}$

After the sol-gel process, the aerogel catalysts' skeleton structure can be completely formed. Compared with the traditional synthetic methods for catalyst materials (such as hydrothermal method, co-precipitation method, and liquid phase reaction method), the synthetic method of the aerogel-based catalyst possesses some specific characteristics that the traditional synthetic methods cannot achieve. In previous years, Schwarz et $a .^{102}$ have comprehensively reported the traditional catalyst synthetic methods mentioned above. In contrast, the synthetic method of the aerogel is more straightforward, which allows the direct in situ compounding of multiple molecules, ions, and particle precursors during the synthetic process. As a product of the sol-gel process, the whole piece of organic-inorganic composite aerogel catalysts can be obtained through the following aging and drying process. Next, we will outline the different synthetic methods of aerogel-based catalysts with the aerogel as the support and provide a comparative analysis of the synthetic steps.

To date, the types of aerogels have been divided into inorganic oxide systems, organic systems, and inorganic-organic composite systems. Carbon aerogels are obtained by carbonizing organic aerogels or using carbon materials such as graphene carbon tubes as the precursors. The functionalized aerogel is a composite material obtained by compounding specific functional metals, molecules, ions, and compounds with the aerogel porous skeleton as a support during the synthesis of the aerogels. For aerogel materials with catalytic function, the type of the supported catalyst can be single-component, dual-component, or multi-component, according to the requirements. Combined with some reported literatures, Fig. 4 summarizes the current routes for preparing various composite aerogel catalysts. ${ }^{96,103}$ In order to ensure that the precursors are fully reacted, the wet gel obtained by the sol-gel process needs to be further aged to enhance the threedimensional skeleton structure of the gel.

Since the sol-gel process of the aerogel is carried out in a liquid phase system, the aging wet gel contains a large concentration of solvents. It is necessary to select a suitable drying method to dry the wet gel to obtain the porous aerogel products. In order to ensure the highly porous structure of the aerogel, the drying process must be carried out without affecting the microstructure of the wet gel. According to different gel systems, subcritical drying, supercritical drying, freeze drying, and vacuum drying methods have been selected to remove the solvent in the wet gel. In general, for the production process of the aerogels, atmospheric drying is the most common and easiest way to achieve them, which is a factor of great significance for the large-scale production of aerogels. However, the pores of the aerogel are at the nanometer-scale, and the internal solvent will generate greater stress due to capillary action during the drying process, which will cause the aerogel microstructure to collapse. In this case, some non-polar functional groups can be introduced to modify the pore surface. At the same time, after the aging process of the wet gel is finished, the low surface tension solvent is used to replace the liquid in the pores to reduce the capillary stress so that aerogels with a complete structure can be prepared. After solvent exchange, the wet gel can be dried by conventional drying methods to obtain solid aerogels. If we want to further increase the specific surface area of the aerogel, supercritical drying is the best choice at present. ${ }^{104}$ This method is to replace the solvents in the wet gel using supercritical $\mathrm{CO}_{2}$ or ethanol as the medium, which can protect the microstructural stability at the largest degree of the aerogels.

For carbonaceous aerogels, the carbonization process is necessary after the drying process. The carbonization process is usually carried out at temperatures above $500{ }^{\circ} \mathrm{C}$ with inert gas protection. With the increase in the temperature, the organic matter is pyrolyzed, and the hydrogen and oxygen in the polymer are gradually volatilized, leaving a porous carbon skeleton. At the same time, the supported catalyst is reduced and crystallized at a high temperature. Fig. 4 shows the synthetic process of the organic-inorganic composite aerogel, and as shown in Fig. 4, before the carbonization process is carried out, one or more kinds of molecules, ions, or particles can be directly compounded in aerogels in this case without affecting the physical properties of the aerogels. ${ }^{105-107}$ In addition, the prepared aerogel can also support the catalyst by immersing the solid aerogel in a metal salt solution or vapor deposition and other methods. These methods are generally considered to be the simplest and economical methods to prepare multiple composite catalysts. In recent years, the development of organic-inorganic multiple composite catalysts has brought great opportunities for applications such as photocatalysis, electrocatalysis, and heterogeneous catalysis. ${ }^{108-110}$ The introduction of some new concepts, such as quantum dots and single atoms, also brings new potentials for aerogel-based catalysts. The development of these cutting-edge aerogel catalysts will certainly push the whole catalytic field to a new stage.

\section{Rational design of single atom aerogel catalyst by host-guest interaction}

The catalytic performance of the catalyst materials is mainly affected by the electronic structure effect and the surface 


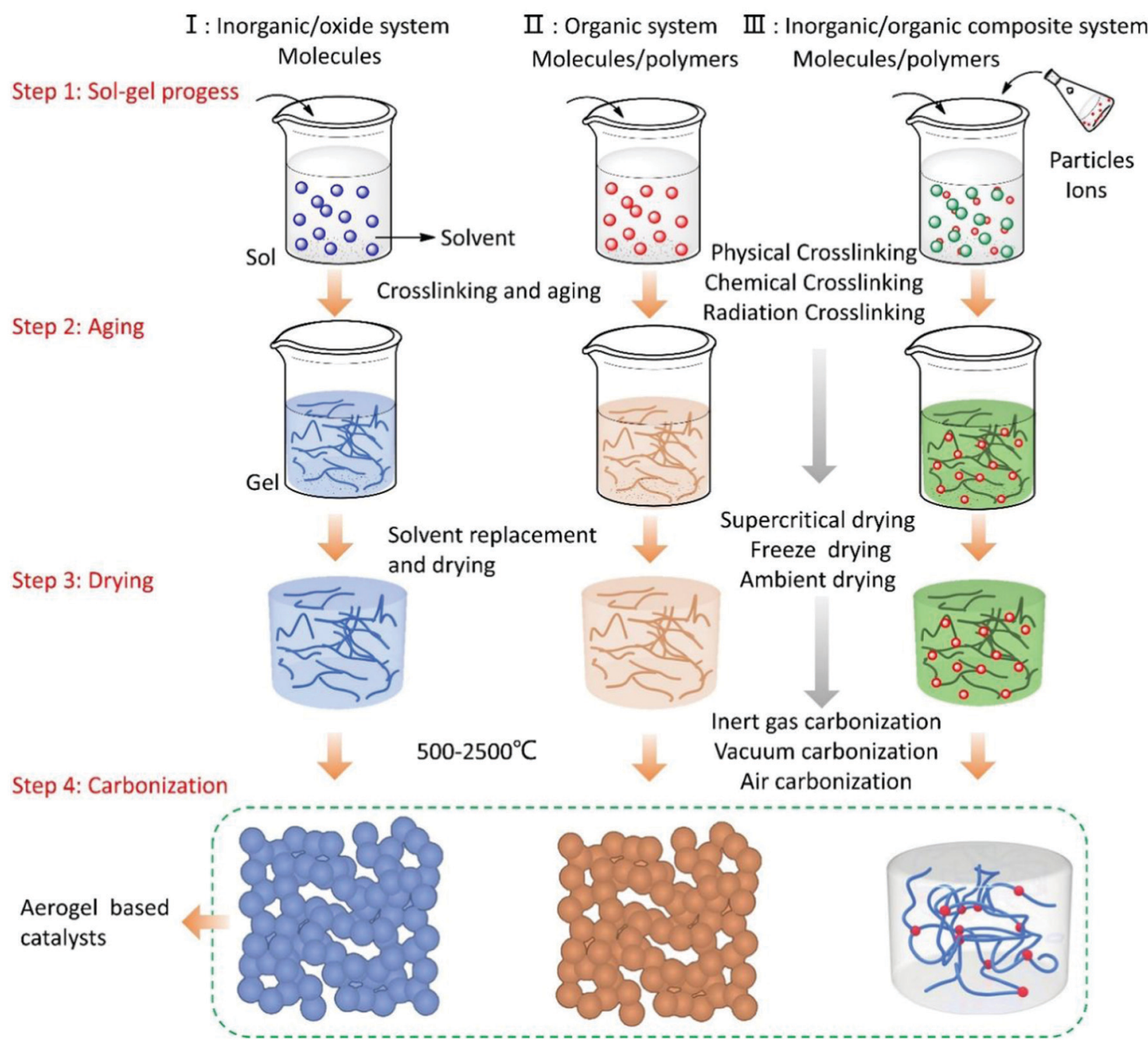

Fig. 4 The synthetic strategies of aerogel-based catalysts.

structure effect. The electronic structure effect mainly includes the influence of the energy band and the surface density of states on the catalytic performance. The surface structure effect mainly refers to the influence of the electronic interaction on the surface interface layer between the catalyst material (the surface chemical structure and the atomic arrangement structure) and the reaction system on the catalytic rate. ${ }^{111,112}$ The influence of the activation energy of the catalyst on the reaction rate is several to dozens of orders of magnitude, while the effect of the surface electric double layer structure on the reaction rate is one to two orders of magnitude. In the practical work of catalysts, the electronic structure effect and the surface structure effect are complementary, and they cannot be completely independent. Even so, the electronic structure effect should be given priority in the selection of the catalyst material system, and the catalyst with low power consumption and high activity can be obtained by selecting the appropriate material system. Some high-frequency reported elements that have been used as the SACs are shown in Fig. $5 .{ }^{6}$ After the catalyst material system is finalized, it is necessary to consider the effect of the catalyst surface structure on the catalytic activity.
According to the electronic structure effect of the material system, the selection of the catalysts is mainly concentrated in VIIIB and IB groups. Every single element or their compounds have their inherent physical and chemical properties. In view of these physical and chemical properties, it is necessary to design a reasonable synthetic method to obtain SACs with sufficient performance. The development direction of noble metal SACs is to reduce the metal content as much as possible under the premise of ensuring catalytic activity, while the development direction of the base metal SACs is to give priority to ensure the catalytic performance. Among the candidate systems of catalyst materials, the most likely substitutes for noble metals are Fe, $\mathrm{Co}, \mathrm{Ni}$, and $\mathrm{Cu}$. Some recent studies have also shown that $\mathrm{Fe}$, $\mathrm{Co}, \mathrm{Ni}$, and their composites possess great potential in the field of SACs. ${ }^{86,113-121}$ Lausanne Institute of technology and National Taiwan University jointly reported a catalyst composed of dispersed monoatomic Fe active sites (Fig. 6). ${ }^{113}$ The catalyst produces carbon monoxide at an overpotential as low as $80 \mathrm{mV}$. At an overpotential of $340 \mathrm{mV}$, the partial current density reaches $94 \mathrm{~mA} \mathrm{~cm}{ }^{-2}$. Du et al. ${ }^{114}$ found that nitrogen-doped graphene-supported cobalt single atom material can trigger the 


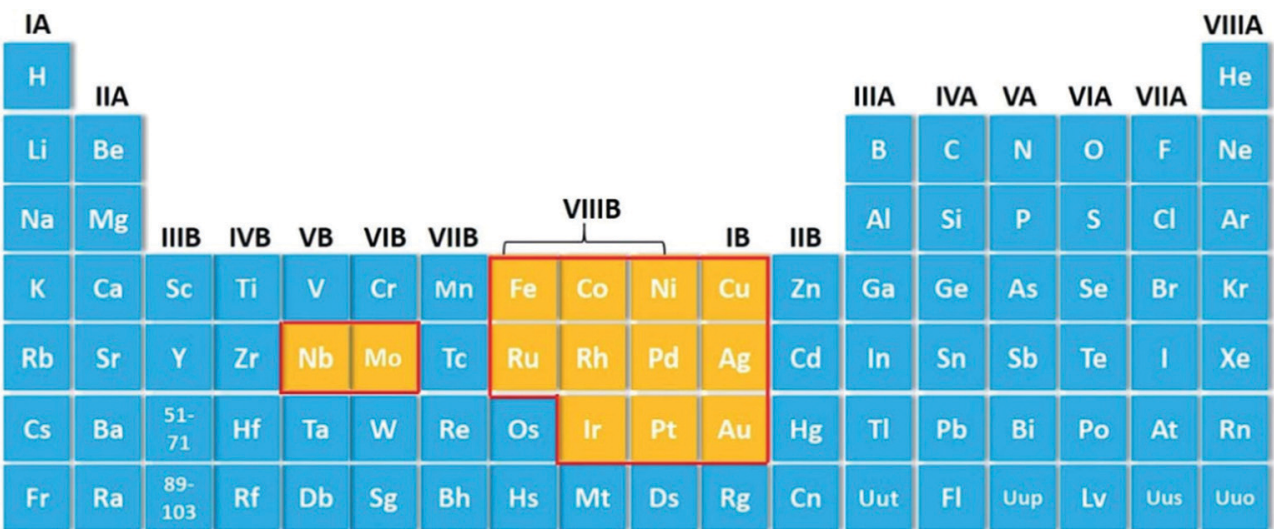

\begin{tabular}{|l|l|l|l|l|l|l|l|l|l|l|l|l|l|l|l|}
$\begin{array}{l}\text { Lanthanide } \\
\text { Series } \\
\text { Actinide }\end{array}$ & La & Ce & Pr & Nd & Pm & Sm & Eu & Gd & Tb & Dy & Ho & Er & Tm & Yb & Lu \\
\hline $\begin{array}{l}\text { Series } \\
\text { Th }\end{array}$ & Pa & U & Np & Pu & Am & Cm & Bk & Cf & Es & Fm & Md & No & Lr \\
\hline
\end{tabular}

Fig. 5 Some high-frequency reported elements that have been used as SACs. ${ }^{6}$ The reported SACs are highlighted in yellow. Copyright 2013 , the Royal Society of Chemistry.
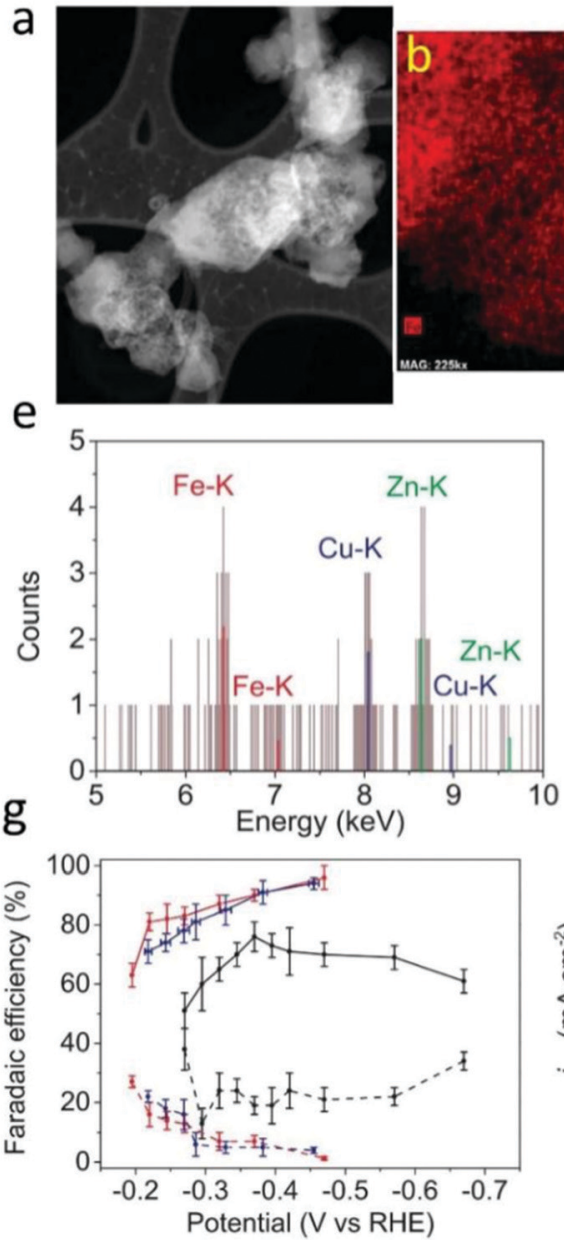
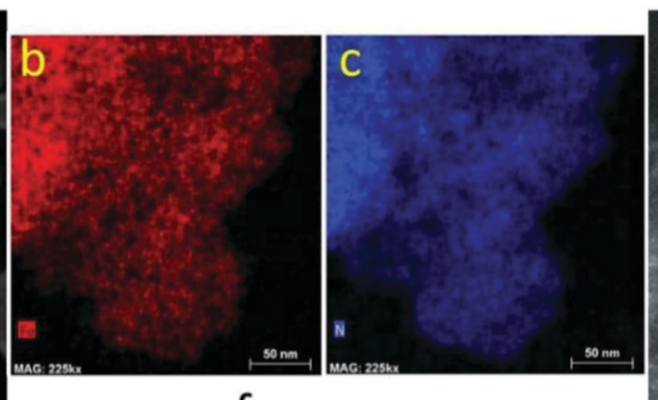

\section{d}
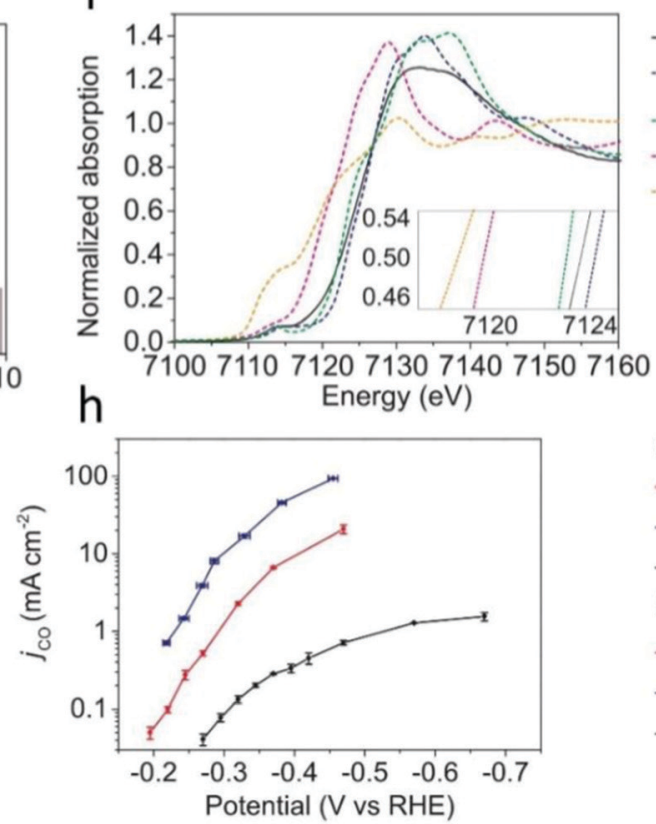

$\mathrm{CO}$

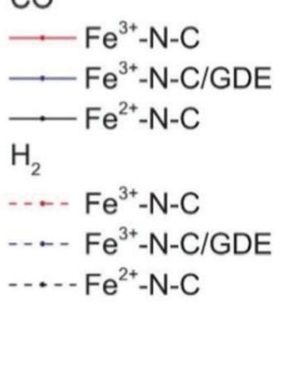

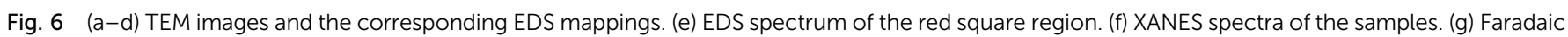
efficiency of $\mathrm{CO}$ and $\mathrm{H}_{2}$ production. (h) The $j_{\mathrm{CO}}$ in an $\mathrm{H}$-cell. Copyright 2019, American Association for the Advancement of Science. 
surface-mediated reaction of lithium polysulfide. A promising lithium sulfur battery with a high specific capacity of $1210 \mathrm{~mA} \mathrm{~h} \mathrm{~g}^{-1}$ and good cycle performance was prepared.

Through a series of systematic investigations on the physical and chemical properties of these base metals of $\mathrm{Fe}, \mathrm{Co}, \mathrm{Ni}$, and their compounds, and we have also found some valuable information. $\mathrm{Fe}, \mathrm{Co}$, and Ni can form organic transition metal compounds with aromatic properties such as ferrocene, cobaltocene, and nickelocene. These compounds exhibit some unique properties; Masaki et al. ${ }^{122}$ invented a supramolecular hydrogel actuator driven by the redox reaction, which exploits the mechanism of the host-guest interaction. As shown in Fig. $7 \mathrm{a}-\mathrm{c}$, the gel network of the hydrogel drivers consists of
$\mathrm{N}, \mathrm{N}$-methylenebisacrylamide-crosslinked poly(acrylamide) grafted with two functional molecules, beta-cyclodextrin and ferrocene, which make the hydrogel network exhibit redox expansioncontraction function through host-guest interactions between these two molecules. Duan et al. ${ }^{123}$ synthesized ferrocenecellulose with a substitution degree of $0.5 \mathrm{wt} \%$ and betacyclodextrin-chitosan with a substitution degree of $0.35 \mathrm{wt} \%$, and then synthesized the cellulose-chitosan gel with these two polysaccharides. Benefiting from intermolecular inclusion, the cut gel showed self-healing ability after 24 hours (Fig. $7 d$ and e). Similarly, Fig. $7 \mathrm{f}$ further demonstrates the reaction mechanism during the self-healing process of cyclodextrin and ferrocene. The special properties of the first three materials have one a

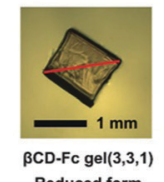

Reduced form

b
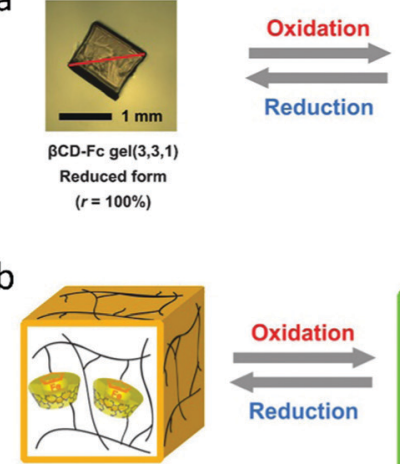

Reduction

(1)
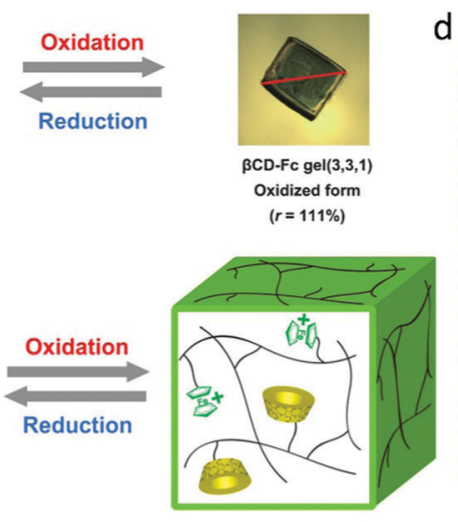

d
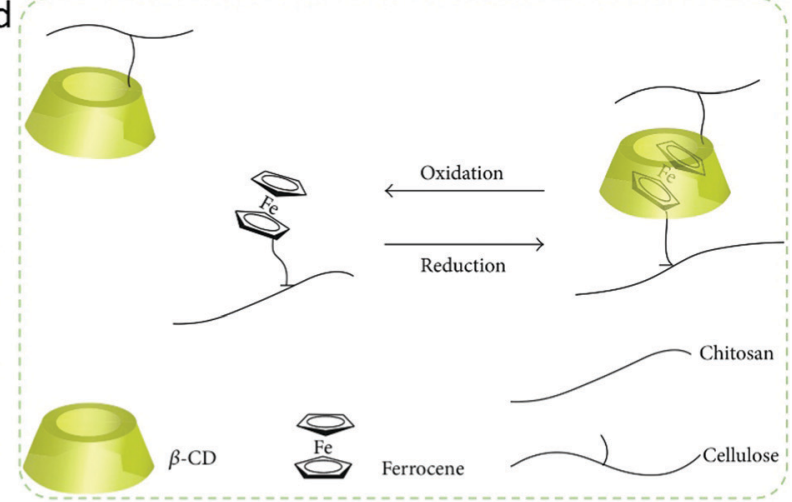

e
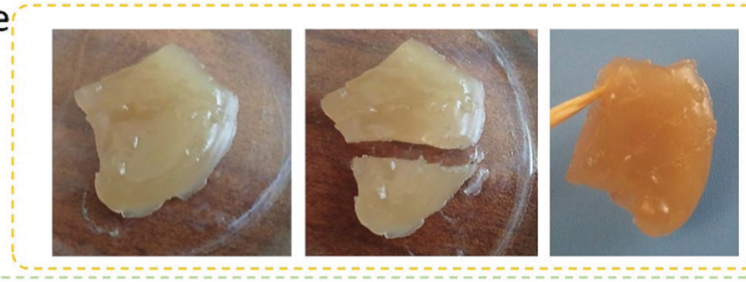

$\mathrm{f}$
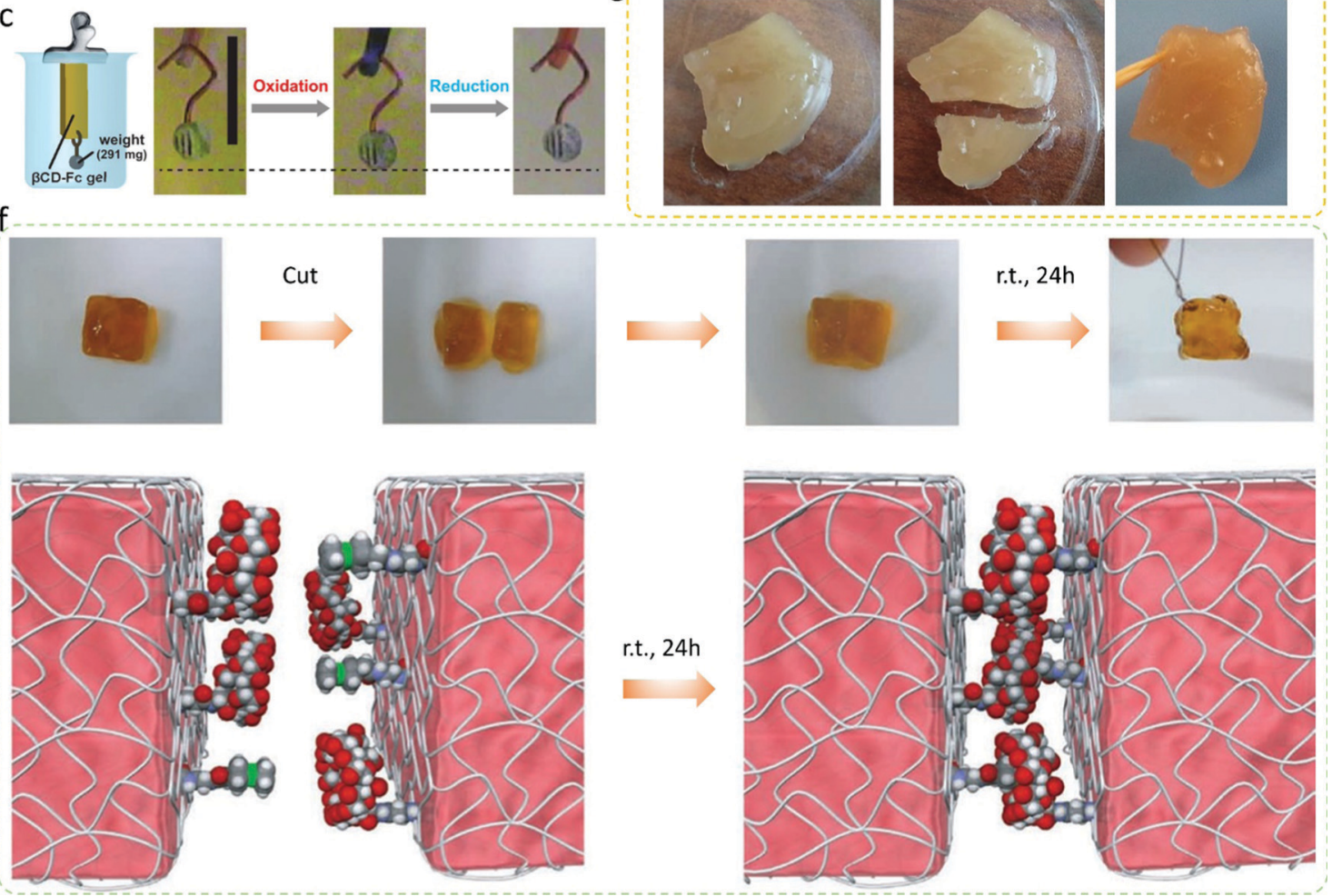

Fig. 7 (a) Photographs of the gel. (b) Illustration of redox-responsive expansion contraction of the gel. (c) Illustration of the gel actuator in response to the redox stimuli. ${ }^{122}$ Copyright 2013, Wiley-VCH Verlag GmbH \& Co. KGaA, Weinheim. (d) Intermolecular inclusion interaction of the hydrogel. (e) Selfhealing experiments. ${ }^{123}$ Copyright 2015, Hindawi Publishing Corporation. (f) Photographs and schematic diagram of the self-healing experiments. ${ }^{124}$ Copyright 2011, Nature. 
thing in common, i.e., the use of the host and guest functions of ferrocene and cyclodextrin. This special property also brings some enlightenment to the synthesis of single atom materials.

After discovering this particular property, we evaluated this series of organic transition metal compounds. In addition to ferrocene, there are similar organic transition metal compounds such as nickel and cobalt. As shown in Fig. 8a, metallocene (general formula $\left(\eta^{5}-\mathrm{C}_{5} \mathrm{H}_{5}\right)_{2} \mathrm{M}$ or $\left.(\mathrm{CP})_{2} \mathrm{M}\right)$ is the generic name of dicyclopentadiene-based metal coordination compounds.
Among them, $\mathrm{M}$ mainly refers to transition metals, while both cyclopentadienyl groups $\left(\mathrm{CP}=\mathrm{C}_{5} \mathrm{H}_{5}\right)$ are pentadentate ligands, similar to two pieces of bread, and sandwich metal $\mathrm{M}$ is in the middle; thus, they are commonly known as sandwich compounds. Cyclodextrin (CD) is a general term for a series of cyclic oligosaccharides produced by amylose under the action of cyclodextrin glucosyltransferase produced by Bacillus sp., usually containing 6-12 D-glucopyranose units. Among them, the most studied and important practical significance is the molecule containing 6, 7,

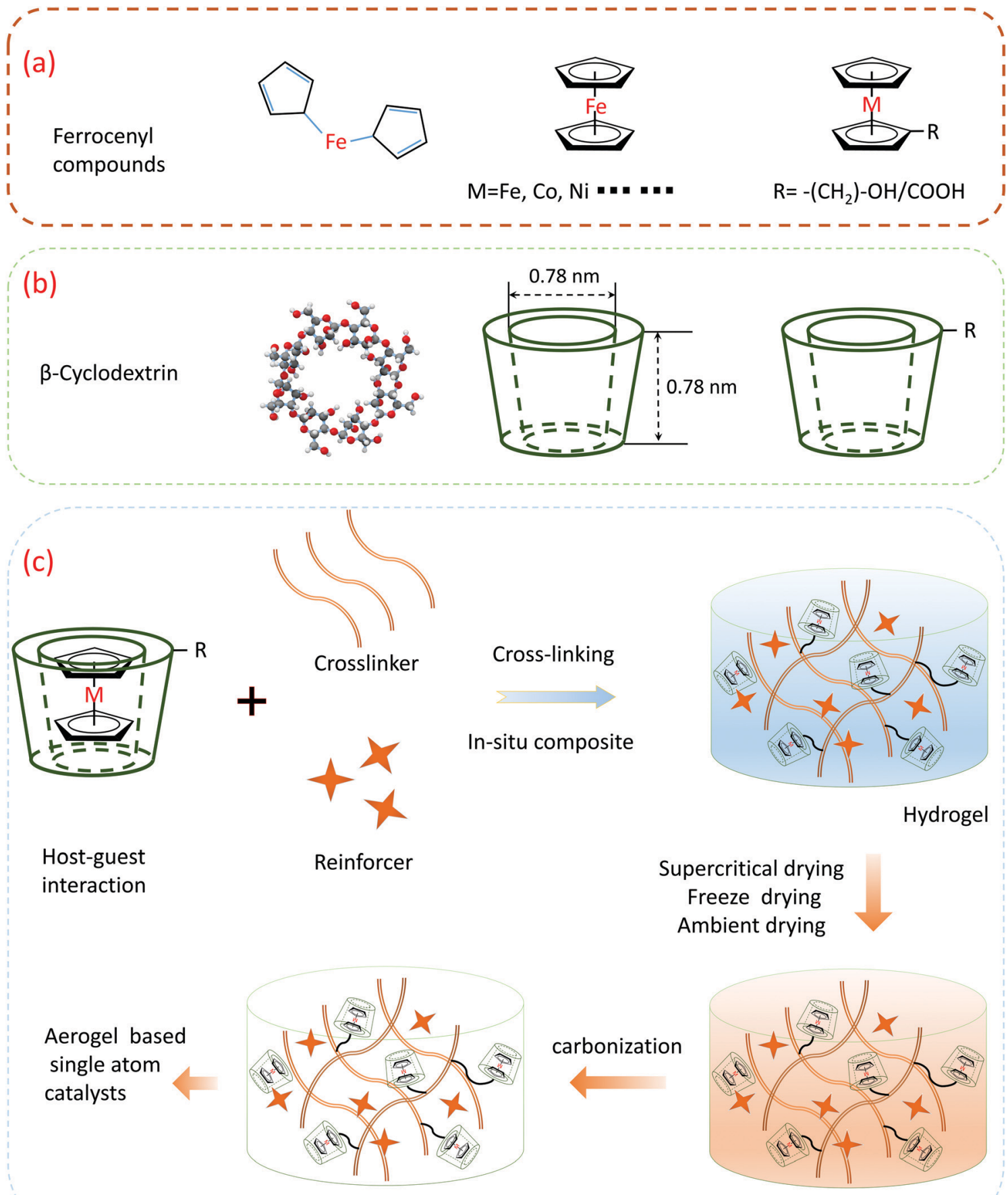

Fig. 8 The synthetic strategy of single atom aerogel catalyst by the host-guest interaction. 
and 8 glucose units, which are called alpha-, beta-, and gamacyclodextrins, respectively (Fig. 8b). The upper end of the outer side of the cyclodextrin molecule (larger open end) is composed of C2 and C3 secondary hydroxyl groups, and the lower end (smaller open end) is composed of C6 primary hydroxyl groups, which is hydrophilic. The cavity is affected by the $\mathrm{C}-\mathrm{H}$ bond and the shielding effect forms a hydrophobic zone. Because the outer edge of cyclodextrin is hydrophilic while the inner cavity is hydrophobic, it can provide a hydrophobic binding site, such as an enzyme, as the main body (host) envelopes various appropriate objects (guest), such as organic molecules, inorganic ions, and gas molecules.

This atomic-level confinement effect is one of the most favorable factors for the synthesis of single atom materials. As shown in Fig. 8c, using the host-guest interactions of cyclodextrin and ferrocene, after ferrocene enters the cyclodextrin cavity, the iron atoms in the ferrocene will be restricted by the cyclopentadiene molecule up and down, and the iron atom is limited by the surrounding cyclodextrin, i.e., after the inclusion of the host and the guest, the position of the iron atom cannot move at all, which establishes a prerequisite for the later synthesis of single iron sites. The inclusion products can be directly used for the synthesis of monoatomic materials after separation and drying. Another synthetic route is to add an appropriate crosslinking agent and some other functional molecules or nanoparticles into the system to form a hydrogel in situ, and then form an aerogel-based single atom material after aging, drying, and carbonization. Through the implementation of this strategy, it has an auxiliary effect on the full synthetic process of the single-atom catalyst in the pre-middle and late stages.

At present, single-atom catalysts still need to face many challenges before they are transformed into mature commercial products. As shown in Fig. 9, the first one is that singleatom materials are easy to agglomerate during the synthetic process and it is difficult to ensure the independence of atoms. The second is that it is difficult to increase the loading of single atoms. Once the atomic content increases, it will cause the atoms to reunite and lose the advantages of single atom materials. The third is that due to cost and technology constraints, it is difficult to mass-produce single atom materials. The fourth is that some of the precursors used in the synthetic process of single atom materials are expensive, which violates the original intention of single atom materials to reduce the costs, improve the performance, and restrict their practical use. The last key issue is environmental protection. Single atom materials designed by researchers need to overcome the issues of adopting environment-friendly precursors and low-power preparation processes into consideration. For the challenges we are currently facing, we must consider comprehensively and propose reasonable solutions to each problem. The selection of the precursor, the selection of the synthetic system, and the determination of the synthetic process need to be considered comprehensively. The choice of the precursors is particularly critical. Each precursor has its inherent physical and chemical properties. For different physical and chemical properties, a suitable synthetic scheme needs to be designed. Choosing a suitable precursor can achieve twice the result with half the effort.

Herein, we design a possible experimental scheme based on the current literature reports. Ferrocene and cyclodextrin are used as the precursors. In the early stage of synthesis, hostguest inclusion complexes between cyclodextrin and ferrocene are used to form the inclusion complexes, and the sufficient isolation of iron atoms can inhibit iron atom agglomeration to a certain extent in the late synthetic process. During the subsequent mid-term synthesis, inclusion complexes can be directly added to the cross-linker to form gels using functional groups on polysaccharides or implanting into other gel systems. The gels will form a three-dimensional network structure and undergo supercritical or freeze-drying, which further isolates the iron atoms in space and inhibits atom aggregation during later carbonization. In this way, the iron atoms are well isolated throughout the synthetic phase of the material. Due to

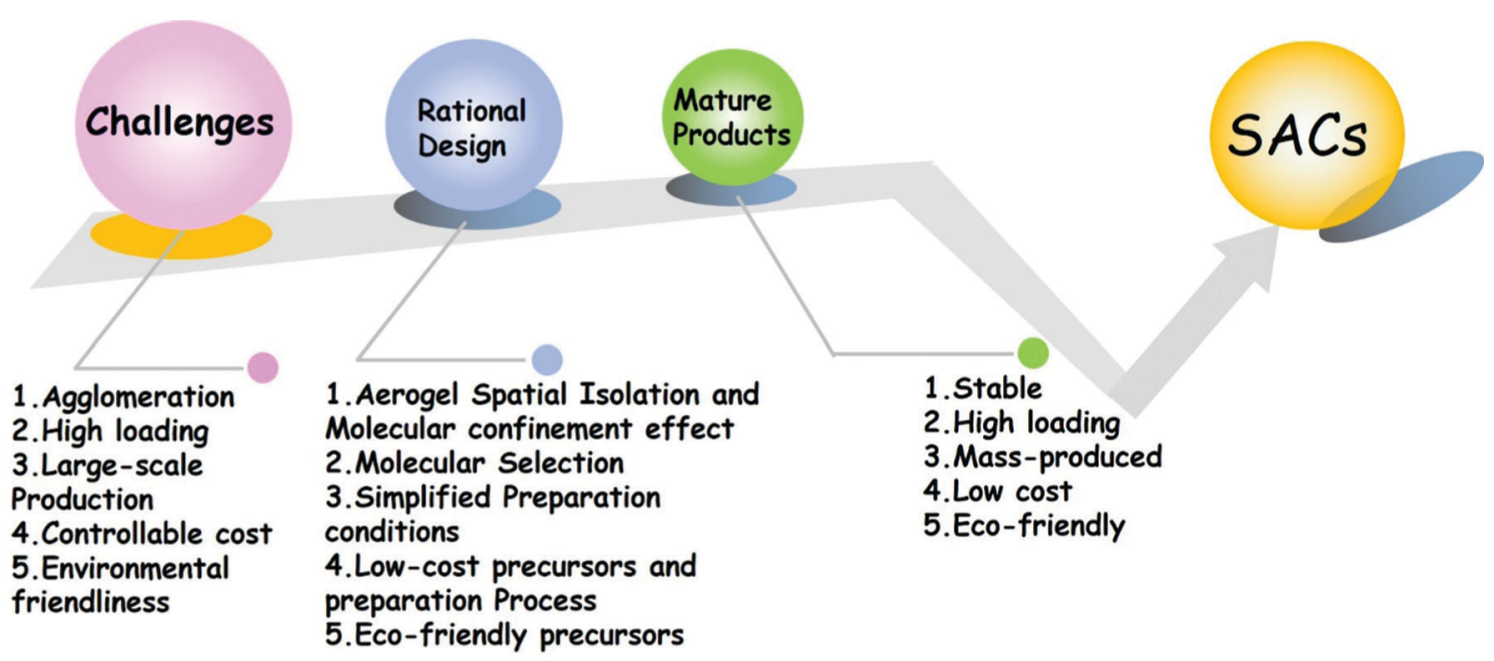

Fig. 9 Current challenges and some possible solutions of SACs. 
Table 2 The metal loading design of single atom catalysts by the host-guest interaction

\begin{tabular}{|c|c|c|c|c|}
\hline Category & $\begin{array}{l}\beta \text {-Cyclodextrin } \\
(\beta \text {-CD })\end{array}$ & $\begin{array}{l}\text { Hydroxypropyl- } \beta \text {-cyclodextrin } \\
\text { (HP- } \beta \text {-CD) }\end{array}$ & Ferrocene & Nickelocene \\
\hline Molecular formula & $\mathrm{C}_{42} \mathrm{H}_{70} \mathrm{O}_{35}$ & $\left(\mathrm{C}_{42} \mathrm{H}_{70} \mathrm{O}_{35}\right)-\mathrm{H}_{X}+\left(\mathrm{C}_{3} \mathrm{H}_{7} \mathrm{O}_{2}\right)_{X}$ & $\mathrm{C}_{10} \mathrm{H}_{10} \mathrm{Fe}$ & $\mathrm{C}_{10} \mathrm{H}_{10} \mathrm{Ni}$ \\
\hline Molecular weight & 1134 & $1431-1806$ & 186.03 & 188.88 \\
\hline Carbon content $^{a}$ & $44.44 \%$ & $44.44-45.3 \%$ & $64.5 \%$ & 63.5 \\
\hline Metal content ${ }^{b}$ & 0 & 0 & $30.1 \%$ & $31.2 \%$ \\
\hline Carbon $/$ metal $^{c}$ & $504 / 0$ & $648 / 0$ & $120 / 56$ & $120 / 59$ \\
\hline Metal/carbon $^{d}$ & 0 & 0 & $\begin{array}{l}6.8 \mathrm{wt} \%(\mathrm{HP}-\beta-\mathrm{CD}), \\
8.2 \mathrm{wt} \%(\beta-\mathrm{CD})\end{array}$ & $\begin{array}{l}7.1 \mathrm{wt} \%(\mathrm{HP}-\beta-\mathrm{CD}) \text {, } \\
8.6 \mathrm{wt} \%(\beta-\mathrm{CD})\end{array}$ \\
\hline
\end{tabular}

${ }^{a}$ Carbon content (wt\%) in the molecule. ${ }^{b}$ Metal content (wt\%) in the molecule. ${ }^{c}$ The ratio of carbon and metal in the molecule. ${ }^{d}$ The weight ratio of carbon and metal when the metal and CD are combined in the molar ratio of $1: 1$. The calculation process takes carbon as the main reference, and the doping of other heteroatoms will change its proportion to a certain extent.

the maximum utilization of atoms and molecules, this is also in line with the atom economy proposed today. Through theoretical calculations, the theoretical maximum content of iron atoms can reach $8.2 \mathrm{wt} \%$ (Table 2). These calculation processes make carbon the main reference, and the doping of other heteroatoms will change its proportion to a certain extent. After doping with other elements, the iron atom content will be reduced but it is also much higher than the current mainstream level.

In addition to inhibiting agglomeration and high loading, this strategy also has obvious advantages in other aspects. Firstly, the inclusion process is a thermodynamic spontaneous process and does not require additional chemical reactions or energy supply. Secondly, the inclusion process is directly realized in the aqueous system without additional organic solvents. In the subsequent hydrogel synthesis process, the aqueous solution system is more environment-friendly and has lower cost than the organic solvent system. The obtained hydrogel can be freeze-dried instead of supercritical drying to simplify the process and control the cost. In addition, ferrocene is a mature and cheap industrial raw material, and cyclodextrin is a natural polysaccharide macromolecular material. Both precursors meet the needs of low cost and environmental friendliness. In addition to ferrocene, there are some other molecules with similar properties that can also be used to synthesize SAC materials in this way and even synthesize diatomic or multiple single atom synergistic composite materials. Only when comprehensively considering all the factors and solving all the challenges can we obtain stable, high-loading, environmentfriendly, low cost, and mass-produced SAC materials.

\section{Conclusion and future perspective}

In summary, high-loading single-atom catalysts have become an important research direction, which cannot be ignored in the development of single-atom catalysts. The main goal of the rapidly developing field of single-atom catalysis is to maximize the loading of the metal atoms in the catalyst without the agglomeration of atoms. Thus, single-atom catalysts exhibit sufficient catalytic activity to ensure practicability. Meanwhile, the following issues should be considered, such as the ease of technology, the environment-friendly synthetic process, the controllable cost of raw materials, and the feasibility of largescale production. In addition to traditional experimental research methods, some theoretical calculations and simulations such as DFT and material genes can also be used for the high throughput screening of the material systems, and they can be combined with new technologies such as artificial intelligence technology brought about by deep learning and machine learning. ${ }^{125-128}$ With the deepening of research and technological evolution, the difficulties faced by single-atom catalysts will be solved one by one, and the potential of singleatom catalysts will be further highlighted.

\section{Conflicts of interest}

The authors declare no competing financial interest.

\section{Acknowledgements}

The authors gratefully acknowledge the support by Sichuan Science and Technology Program of 2021YFH0126.

\section{References}

1 K. Liu, J. Fu, L. Zhu, X. Zhang, H. Li, H. Liu, J. Hu and M. Liu, Nanoscale, 2020, 12, 4903-4908.

2 R. Lang, T. Li, D. Matsumura, S. Miao, Y. Ren, Y. T. Cui, Y. Tan, B. Qiao, L. Li, A. Wang, X. Wang and T. Zhang, Angew. Chem., 2016, 55, 16054-16058.

3 Y. Zhou, G. Gao, W. Chu and L.-W. Wang, Nanoscale, 2021, 13, 1331-1339.

4 K. Chi, Z. Chen, F. Xiao, W. Guo, W. Xi, J. Liu, H. Yan, Z. Zhang, J. Xiao, J. Liu, J. Luo, S. Wang and K. P. Loh, J. Mater. Chem. A, 2019, 7, 15575-15579.

5 S. Wang, J. Li, Q. Li, X. Bai and J. Wang, Nanoscale, 2020, 12, 364-371.

6 H. Yan, C. Su, J. He and W. Chen, J. Mater. Chem. A, 2018, 6, 8793-8814.

7 Q. Wu, J. Wang, Z. Wang, Y. Xu, Z. Xing, X. Zhang, Y. Guan, G. Liao and X. Li, J. Mater. Chem. A, 2020, 8, 13685-13693.

8 Z. Ma, Z. Cui, C. Xiao, W. Dai, Y. Lv, Q. Li and R. Sa, Nanoscale, 2020, 12, 1541-1550. 
9 S. Wang, H. Chen, J. Liao, Q. Sun, F. Zhao, J. Luo, X. Lin, X. Niu, M. Wu, R. Li and X. Sun, ACS Energy Lett., 2019, 4, 755-762.

10 W. Zhao, J. Wang, R. Yin, B. Li, X. Huang, L. Zhao and L. Qian, J. Colloid Interface Sci., 2020, 564, 28-36.

11 H. Jin, S. Sultan, M. Ha, J. N. Tiwari, M. G. Kim and K. S. Kim, Adv. Funct. Mater., 2020, 30, 2000531.

12 M. D. Marcinkowski, S. F. Yuk, N. Doudin, R. S. Smith, M.-T. Nguyen, B. D. Kay, V.-A. Glezakou, R. Rousseau and Z. Dohnálek, ACS Catal., 2019, 9, 10977-10982.

13 C. Ling, L. Shi, Y. Ouyang, X. C. Zeng and J. Wang, Nano Lett., 2017, 17, 5133-5139.

14 X. Yang, J. Cheng, B. Fang, X. Xuan, N. Liu, X. Yang and J. Zhou, Nanoscale, 2020, 12, 18437-18445.

15 X. Li, W. Bi, L. Zhang, S. Tao, W. Chu, Q. Zhang, Y. Luo, C. Wu and Y. Xie, Adv. Mater., 2016, 28, 2427-2431.

16 Z. Wang, J. Yang, J. Gan, W. Chen, F. Zhou, X. Zhou, Z. Yu, J. Zhu, X. Duan and Y. Wu, J. Mater. Chem. A, 2020, 8, 10755-10760.

17 R. Hu, Y. Li, F. Wang and J. Shang, Nanoscale, 2020, 12, 20413-20424.

18 H. Yin, S.-L. Li, L.-Y. Gan and P. Wang, J. Mater. Chem. A, 2019, 7, 11908-11914.

19 Z. Kou, W. Zang, W. Pei, L. Zheng, S. Zhou, S. Zhang, L. Zhang and J. Wang, J. Mater. Chem. A, 2020, 8, 3071-3082.

20 L. Zeng, C. Dai, B. Liu and C. Xue, J. Mater. Chem. A, 2019, 7, 24217-24221.

21 Q. Bi, X. Yuan, Y. Lu, D. Wang, J. Huang, R. Si, M. Sui and F. Huang, Research, 2020, 2020, 9140841.

22 X. Jin, R. Wang, L. Zhang, R. Si, M. Shen, M. Wang, J. Tian and J. Shi, Angew. Chem., Int. Ed., 2020, 59, 6827-6831.

23 Z. Chen, Z. Xu, W. Li, C. Chen, J. Yang, J. Liu, F. Gong, J. Liao and M. Wu, ACS Appl. Energy Mater., 2019, 2, 5171-5182.

24 Z. Wang, J. Yang, J. Cao, W. Chen, G. Wang, F. Liao, X. Zhou, F. Zhou, R. Li, Z. Q. Yu, G. Zhang, X. Duan and Y. Wu, ACS Nano, 2020, 14, 6164-6172.

25 Y. Yao, Z. Huang, P. Xie, L. Wu, L. Ma, T. Li, Z. Pang, M. Jiao, Z. Liang, J. Gao, Y. He, D. J. Kline, M. R. Zachariah, C. Wang, J. Lu, T. Wu, T. Li, C. Wang, R. ShahbazianYassar and L. Hu, Nat. Nanotechnol., 2019, 14, 851-857.

26 P. A. Szilagyi, D. M. Rogers, I. Zaiser, E. Callini, S. Turner, A. Borgschulte, A. Zuettel, H. Geerlings, M. Hirscher and B. Dam, J. Mater. Chem. A, 2017, 5, 15559-15566.

27 Y. Feng, Y. Guan, H. Zhang, Z. Huang, J. Li, Z. Jiang, X. Gu and Y. Wang, J. Mater. Chem. A, 2018, 6, 11783-11789.

28 H. Zhang, G. Liu, L. Shi and J. Ye, Adv. Energy Mater., 2018, 8, 1701343.

29 H. Zhang, W. Tian, X. Duan, H. Sun, S. Liu and S. Wang, Adv. Mater., 2019, 32, 1904037.

30 L. Zhang, K. Doyle-Davis and X. Sun, Energy Environ. Sci., 2019, 12, 492-517.

31 L. Zhang, H. Liu, S. Liu, M. Norouzi Banis, Z. Song, J. Li, L. Yang, M. Markiewicz, Y. Zhao, R. Li, M. Zheng, S. Ye, Z.-J. Zhao, G. A. Botton and X. Sun, ACS Catal., 2019, 9, 9350-9358.
32 L. Zhang, R. Long, Y. Zhang, D. Duan, Y. Xiong, Y. Zhang and Y. Bi, Angew. Chem., Int. Ed., 2020, 59, 6224-6229.

33 Z. Zhang, Y. Chen, L. Zhou, C. Chen, Z. Han, B. Zhang, Q. Wu, L. Yang, L. Du, Y. Bu, P. Wang, X. Wang, H. Yang and Z. Hu, Nat. Commun., 2019, 10, 1657.

34 Z. Zhang, Y. Zhu, H. Asakura, B. Zhang, J. Zhang, M. Zhou, Y. Han, T. Tanaka, A. Wang, T. Zhang and N. Yan, Nat. Commun., 2017, 8, 16100.

35 X. Zhou, M. Zhu and L. Kang, Catalysts, 2019, 9, 808.

36 G. Zhou, S. Zhao, T. Wang, S. Z. Yang, B. Johannessen, H. Chen, C. Liu, Y. Ye, Y. Wu, Y. Peng, C. Liu, S. P. Jiang, Q. Zhang and Y. Cui, Nano Lett., 2020, 20, 1252-1261.

37 S. Zhou, L. Shang, Y. Zhao, R. Shi, G. I. N. Waterhouse, Y. C. Huang, L. Zheng and T. Zhang, Adv. Mater., 2019, 31, e1900509.

38 C. Zhu, S. Fu, Q. Shi, D. Du and Y. Lin, Angew. Chem., Int. Ed., 2017, 56, 13944-13960.

39 S. Das, R. Ghosh, P. Routh, A. Shit, S. Mondal, A. Panja and A. K. Nandi, ACS Appl. Nano Mater., 2018, 1, 2306-2316.

40 G. Fu, X. Yan, Y. Chen, L. Xu, D. Sun, J. M. Lee and Y. Tang, Adv. Mater., 2018, 30, 1704609.

41 Q. Gao, X. Wang, Z. Shi, Z. Ye, W. Wang, N. Zhang, Z. Hong and M. Zhi, Chem. Eng. J., 2018, 331, 185-193.

42 Y. Gu, S. Chen, J. Ren, Y. A. Jia, C. Chen, S. Komarneni, D. Yang and X. Yao, ACS Nano, 2018, 12, 245-253.

43 Y. Jin, F. Chen, J. Wang, L. Guo, T. Jin and H. Liu, J. Power Sources, 2019, 435, 226798.

$44 \mathrm{~S}$. Montes and H. Maleki, Colloidal Metal Oxide Nanoparticles, 2020, pp. 337-399, DOI: 10.1016/b978-0-12813357-6.00015-2.

45 P. Shanmugam, A. P. Murthy, J. Theerthagiri, W. Wei, J. Madhavan, H.-S. Kim, T. Maiyalagan and J. Xie, Int. J. Hydrogen Energy, 2019, 44, 13334-13344.

46 M. B. Gawande, P. Fornasiero and R. Zbořil, ACS Catal., 2020, 10, 2231-2259.

47 B. Singh, V. Sharma, R. P. Gaikwad, P. Fornasiero, R. Zboril and M. B. Gawande, Small, 2021, 17, e2006473.

48 A. Bakandritsos, R. G. Kadam, P. Kumar, G. Zoppellaro, M. Medved, J. Tucek, T. Montini, O. Tomanec, P. Andryskova, B. Drahos, R. S. Varma, M. Otyepka, M. B. Gawande, P. Fornasiero and R. Zboril, Adv. Mater., 2019, 31, 1970125.

49 D. Yang, S. O. Odoh, T. C. Wang, O. K. Farha, J. T. Hupp, C. J. Cramer, L. Gagliardi and B. C. Gates, J. Am. Chem. Soc., 2015, 137, 7391-7396.

50 D. Yardimci, P. Serna and B. C. Gates, ACS Catal., 2012, 2, 2100-2113.

51 M. Yang, L. F. Allard and M. Flytzani-Stephanopoulos, J. Am. Chem. Soc., 2013, 135, 3768-3771.

52 J. Lin, A. Wang, B. Qiao, X. Liu, X. Yang, X. Wang, J. Liang, J. Li, J. Liu and T. Zhang, J. Am. Chem. Soc., 2013, 135, 15314-15317.

53 L. Lin, W. Zhou, R. Gao, S. Yao, X. Zhang, W. Xu, S. Zheng, Z. Jiang, Q. Yu, Y. W. Li, C. Shi, X. D. Wen and D. Ma, Nature, 2017, 544, 80-83.

54 X. G. Guo, G. Z. Fang, G. Li, H. Ma, H. J. Fan, L. Yu, C. Ma, X. Wu, D. H. Deng, M. M. Wei, D. L. Tan, R. Si, S. Zhang, 
J. Q. Li, L. T. Sun, Z. C. Tang, X. L. Pan and X. H. Bao, Science, 2014, 344, 616-619.

55 D. Deng, X. Chen, L. Yu, X. Wu, Q. Liu, Y. Liu, H. Yang, H. Tian, Y. Hu, P. Du, R. Si, J. Wang, X. Cui, H. Li, J. Xiao, T. Xu, J. Deng, F. Yang, P. N. Duchesne, P. Zhang, J. Zhou, L. Sun, J. Li, X. Pan and X. Bao, Sci. Adv., 2015, 1, e1500462. 56 L. Zhang, M. N. Banis and X. L. Sun, Natl. Sci. Rev., 2018, 5, 628.

57 D. Yan, J. Chen and H. Jia, Angew. Chem., Int. Ed., 2020, 59, 13562-13567.

58 J. Liu, X. Kong, L. Zheng, X. Guo, X. Liu and J. Shui, ACS Nano, 2020, 14, 1093-1101.

59 L. Zhang, A. Wang, W. Wang, Y. Huang, X. Liu, S. Miao, J. Liu and T. Zhang, ACS Catal., 2015, 5, 6563-6572.

60 P. Yin, T. Yao, Y. Wu, L. Zheng, Y. Lin, W. Liu, H. Ju, J. Zhu, X. Hong, Z. Deng, G. Zhou, S. Wei and Y. Li, Angew. Chem., Int. Ed., 2016, 55, 10800-10805.

61 X. Wang, W. Chen, L. Zhang, T. Yao, W. Liu, Y. Lin, H. Ju, J. Dong, L. Zheng, W. Yan, X. Zheng, Z. Li, X. Wang, J. Yang, D. He, Y. Wang, Z. Deng, Y. Wu and Y. Li, J. Am. Chem. Soc., 2017, 139, 9419-9422.

62 S. Ji, Y. Chen, Q. Fu, Y. Chen, J. Dong, W. Chen, Z. Li, Y. Wang, L. Gu, W. He, C. Chen, Q. Peng, Y. Huang, X. Duan, D. Wang, C. Draxl and Y. Li, J. Am. Chem. Soc., 2017, 139, 9795-9798.

63 H. Yan, Y. Lin, H. Wu, W. Zhang, Z. Sun, H. Cheng, W. Liu, C. Wang, J. Li, X. Huang, T. Yao, J. Yang, S. Wei and J. Lu, Nat. Commun., 2017, 8, 1070.

64 B. J. O’Neill, D. H. K. Jackson, J. Lee, C. Canlas, P. C. Stair, C. L. Marshall, J. W. Elam, T. F. Kuech, J. A. Dumesic and G. W. Huber, ACS Catal., 2015, 5, 1804-1825.

65 Y. Cao, S. Chen, Q. Luo, H. Yan, Y. Lin, W. Liu, L. Cao, J. Lu, J. Yang, T. Yao and S. Wei, Angew. Chem., Int. Ed., 2017, 56, 12191-12196.

66 C. Wang, X.-K. Gu, H. Yan, Y. Lin, J. Li, D. Liu, W.-X. Li and J. Lu, ACS Catal., 2016, 7, 887-891.

67 M. Nesselberger, M. Roefzaad, R. F. Hamou, P. U. Biedermann, F. F. Schweinberger, S. Kunz, K. Schloegl, G. K. Wiberg, S. Ashton, U. Heiz, K. J. Mayrhofer and M. Arenz, Nat. Mater., 2013, 12, 919-924.

68 M. D. Kane, F. S. Roberts and S. L. Anderson, Faraday Discuss., 2013, 162, 323-340.

69 L. Liu, U. Diaz, R. Arenal, G. Agostini, P. Concepcion and A. Corma, Nat. Mater., 2017, 16, 132-138.

70 C. H. Choi, M. Kim, H. C. Kwon, S. J. Cho, S. Yun, H. T. Kim, K. J. Mayrhofer, H. Kim and M. Choi, Nat. Commun., 2016, 7, 10922.

71 F. Yang, S. Ding, H. Song and N. Yan, Sci. China Mater., 2020, 63, 982-992.

72 F. Su, Y. Li, J. Ma, L. Wang, Z. Zhong, L. Wang, S. Tian, Z. Li, H. Liu, J. Li, Y. Zhu, W. Chen, Y. Ji and Q. Shi, Natl. Sci. Rev., 2020, 7, 600-608.

73 Y. Nakaya, J. Hirayama, S. Yamazoe, K. I. Shimizu and S. Furukawa, Nat. Commun., 2020, 11, 2838.

74 S. He, D. Ji, J. Zhang, P. Novello, X. Li, Q. Zhang, X. Zhang and J. Liu, J. Phys. Chem. B, 2020, 124, 511-518.
75 B. Han, T. Li, J. Zhang, C. Zeng, H. Matsumoto, Y. Su, B. Qiao and T. Zhang, Chem. Commun., 2020, 56, 4870-4873.

76 Y.-N. Gong, L. Jiao, Y. Qian, C.-Y. Pan, L. Zheng, X. Cai, B. Liu, S.-H. Yu and H.-L. Jiang, Angew. Chem., Int. Ed., 2020, 59, 2705-2709.

77 D. Yan, J. Chen and H. Jia, Angew. Chem., Int. Ed., 2020, 59, 13562-13567.

78 C.-C. Hou, L. Zou, L. Sun, K. Zhang, Z. Liu, Y. Li, C. Li, R. Zou, J. Yu and Q. Xu, Angew. Chem., Int. Ed., 2020, 59, 7384-7389.

79 C. Tian, H. Zhang, X. Zhu, B. Lin, X. Liu, H. Chen, Y. Zhang, D. R. Mullins, C. W. Abney, M. Shakouri, R. Chernikov, Y. Hu, F. Polo-Garzon, Z. Wu, V. Fung, D.-e. Jiang, X. Liu, M. Chi, J. Liu Jimmy and S. Dai, Appl. Catal., B, 2020, 261, 118178.

80 G. Ding, L. Hao, H. Xu, L. Wang, J. Chen, T. Li, X. Tu and Q. Zhang, Commun. Chem., 2020, 3, 43.

81 Z. Yang, B. Chen, W. Chen, Y. Qu, F. Zhou, C. Zhao, Q. Xu, Q. Zhang, X. Duan and Y. Wu, Nat. Commun., 2019, 10, 3734 .

82 J. Li, Q. Guan, H. Wu, W. Liu, Y. Lin, Z. Sun, X. Ye, X. Zheng, H. Pan, J. Zhu, S. Chen, W. Zhang, S. Wei and J. Lu, J. Am. Chem. Soc., 2019, 141, 14515-14519.

83 W. Ni, Y. Gao, Y. Zhang, H. A. Younus, X. Guo, C. Ma, Y. Zhang, J. Duan, J. Zhang and S. Zhang, ACS Appl. Mater. Interfaces, 2019, 11, 45825-45831.

84 Q. Wang, X. Huang, Z. L. Zhao, M. Wang, B. Xiang, J. Li, Z. Feng, H. Xu and M. Gu, J. Am. Chem. Soc., 2020, 142, $7425-7433$.

85 L. Zhao, Y. Zhang, L.-B. Huang, X.-Z. Liu, Q.-H. Zhang, C. He, Z.-Y. Wu, L.-J. Zhang, J. Wu, W. Yang, L. Gu, J.-S. Hu and L.-J. Wan, Nat. Commun., 2019, 10, 1278.

86 L. Zhao, Y. Zhang, L. B. Huang, X. Z. Liu, Q. H. Zhang, C. He, Z. Y. Wu, L. J. Zhang, J. Wu, W. Yang, L. Gu, J. S. Hu and L. J. Wan, Nat. Commun., 2019, 10, 1278.

87 X. Xu, H. Chu, Z. Zhang, P. Dong, R. Baines, P. M. Ajayan, J. Shen and M. Ye, ACS Appl. Mater. Interfaces, 2017, 9, 32756-32766.

88 X. Xu, H. Liang, F. Ming, Z. Qi, Y. Xie and Z. Wang, ACS Catal., 2017, 7, 6394-6399.

89 Y. Shang, X. Xu, B. Gao and Z. Ren, ACS Sustainable Chem. Eng., 2017, 5, 8908-8917.

90 H. Maleki and N. Hüsing, Appl. Catal., B, 2018, 221, 530-555.

91 B. Zhang, H. Wang, Z. Zuo, H. Wang and J. Zhang, J. Mater. Chem. A, 2018, 6, 15728-15737.

92 Q. Shi, C. Zhu, H. Zhong, D. Su, N. Li, M. H. Engelhard, H. Xia, Q. Zhang, S. Feng, S. P. Beckman, D. Du and Y. Lin, ACS Energy Lett., 2018, 3, 2038-2044.

93 Y. Zhou, G. Zhang, M. Yu, X. Wang, J. Lv and F. Yang, ACS Sustainable Chem. Eng., 2018, 6, 8437-8446.

94 I. Smirnova and P. Gurikov, J. Supercrit. Fluids, 2018, 134, 228-233.

95 L. Wang, Z. Sofer and M. Pumera, ACS Nano, 2020, 14, 21-25. 
96 H. Maleki, L. Durães and A. Portugal, J. Non-Cryst. Solids, 2014, 385, 55-74.

97 P. H. Mutin and A. Vioux, J. Mater. Chem. A, 2013, 1, 11504.

98 Z. Chen, T. Wang and X. Yan, J. Appl. Polym. Sci., 2017, 134, 44388.

99 Z. Chen, T. Wang and Q. Yan, J. Biomater. Sci., Polym. Ed., 2018, 29, 309-324.

100 Z. Xu, W. Li, Z. Chen, D. Wang, T. Feng, H. Potapenko and M. Wu, Macromol. Mater. Eng., 2019, 304, 1800477.

101 Z. Chen, T. Wang and X. Yan, Mater. Lett., 2017, 197, 156-159.

102 J. A. Schwarz, C. Contescu and A. Contescu, Chem. Rev., 1995, 95, 477-510.

103 M. Schneider and A. Baiker, Catal. Rev., 1995, 37, 515-556.

104 H. Maleki, L. Durães and A. Portugal, J. Phys. Chem. C, 2015, 119, 7689-7703.

105 H. Maleki, L. Durães, B. F. O. Costa, R. F. Santos and A. Portugal, Microporous Mesoporous Mater., 2016, 232, 227-237.

106 D. Nadargi, J. Gurav, M. A. Marioni, S. Romer, S. Matam and M. M. Koebel, J. Colloid Interface Sci., 2015, 459, 123-126.

107 W. H. Lai, Z. Miao, Y. X. Wang, J. Z. Wang and S. L. Chou, Adv. Energy Mater., 2019, 9, 1900722.

108 N. Leventis, N. Chandrasekaran, A. G. Sadekar, S. Mulik and C. Sotiriou-Leventis, J. Mater. Chem., 2010, 20, 7456.

109 S. Mahadik-Khanolkar, S. Donthula, A. Bang, C. Wisner, C. Sotiriou-Leventis and N. Leventis, Chem. Mater., 2014, 26, 1318-1331.

110 W. Liu, A.-K. Herrmann, N. C. Bigall, P. Rodriguez, D. Wen, M. Oezaslan, T. J. Schmidt, N. Gaponik and A. Eychmüller, Acc. Chem. Res., 2015, 48, 154-162.

111 J. Greeley, T. F. Jaramillo, J. Bonde, I. B. Chorkendorff and J. K. Norskov, Nat. Mater., 2006, 5, 909-913.

112 J. K. Norskov, J. Rossmeisl, A. Logadottir, L. Lindqvist, J. R. Kitchin, T. Bligaard and H. Jonsson, J. Phys. Chem. B, 2004, 108, 17886-17892.
113 J. Gu, C.-S. Hsu, L. Bai, H. M. Chen and X. Hu, Science, 2019, 364, 1091.

114 Z. Du, X. Chen, W. Hu, C. Chuang, S. Xie, A. Hu, W. Yan, X. Kong, X. Wu, H. Ji and L. J. Wan, J. Am. Chem. Soc., 2019, 141, 3977-3985.

115 Y. Hou, M. Qiu, M. G. Kim, P. Liu, G. Nam, T. Zhang, X. Zhuang, B. Yang, J. Cho, M. Chen, C. Yuan, L. Lei and X. Feng, Nat. Commun., 2019, 10, 1392.

116 Y. Gao, Z. Cai, X. Wu, Z. Lv, P. Wu and C. Cai, ACS Catal., 2018, 8, 10364-10374.

117 J. Yang, Z. Qiu, C. Zhao, W. Wei, W. Chen, Z. Li, Y. Qu, J. Dong, J. Luo, Z. Li and Y. Wu, Angew. Chem., Int. Ed., 2018, 57, 14095-14100.

118 Z. Gao, W. Yang, X. Ding, G. Lv and W. Yan, Appl. Surf. Sci., 2018, 436, 585-595.

119 Z. K. Yang, C.-Z. Yuan and A.-W. Xu, Nanoscale, 2018, 10, 16145-16152.

120 Y. Xue, B. Huang, Y. Yi, Y. Guo, Z. Zuo, Y. Li, Z. Jia, H. Liu and Y. Li, Nat. Commun., 2018, 9, 1460.

121 G. Wan, P. Yu, H. Chen, J. Wen, C. J. Sun, H. Zhou, N. Zhang, Q. Li, W. Zhao, B. Xie, T. Li and J. Shi, Small, 2018, 14, e1704319.

122 M. Nakahata, Y. Takashima, A. Hashidzume and A. Harada, Angew. Chem., Int. Ed., 2013, 52, 5731-5735.

123 J. Duan, C. Han, L. Liu, J. Jiang, J. Li, Y. Li and C. Guan, J. Spectrosc., 2015, 2015, 1-6.

124 M. Nakahata, Y. Takashima, H. Yamaguchi and A. Harada, Nat. Commun., 2011, 2, 511.

125 Y.-F. Wang, K. Li and G.-C. Wang, Appl. Surf. Sci., 2018, 436, 631-638.

126 K. Alexopoulos, Y. Wang and D. G. Vlachos, ACS Catal., 2019, 9, 5002-5010.

127 J. Hwang, S. H. Noh and B. Han, Appl. Surf. Sci., 2019, 471, 545-552.

128 K. Alexopoulos and D. G. Vlachos, Chem. Sci., 2020, 11, 1469-1477. 